\title{
Clinical Pharmacokinetics of Triazoles in Pediatric Patients
}

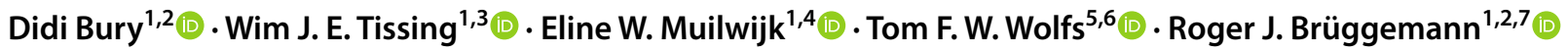

Accepted: 28 January 2021 / Published online: 18 May 2021

(c) The Author(s) 2021

\begin{abstract}
Triazoles represent an important class of antifungal drugs in the prophylaxis and treatment of invasive fungal disease in pediatric patients. Understanding the pharmacokinetics of triazoles in children is crucial to providing optimal care for this vulnerable population. While the pharmacokinetics is extensively studied in adult populations, knowledge on pharmacokinetics of triazoles in children is limited. New data are still emerging despite drugs already going off patent. This review aims to provide readers with the most current knowledge on the pharmacokinetics of the triazoles: fluconazole, itraconazole, voriconazole, posaconazole, and isavuconazole. In addition, factors that have to be taken into account to select the optimal dose are summarized and knowledge gaps are identified that require further research. We hope it will provide clinicians guidance to optimally deploy these drugs in the setting of a life-threatening disease in pediatric patients.
\end{abstract}

\section{Introduction}

Immunocompromised pediatric patients are at high risk for invasive fungal disease (IFD). Although advances have been made in the management of IFD, the incidence and mortality rates are still high whereas treatment options remain limited and challenging. Triazoles represent the most important class of antifungal drugs for the prophylaxis and treatment of IFD. Within this class, isavuconazole, itraconazole,

Roger J. Brüggemann

Roger.Bruggemann@radboudumc.nl

1 Department of Supportive Care, Princess Máxima Center for Pediatric Oncology, Utrecht, The Netherlands

2 Department of Pharmacy, Radboud Institute for Health Sciences, Radboud University Medical Center, Nijmegen, The Netherlands

3 Department of Pediatric Oncology, University of Groningen, University Medical Center Groningen, Groningen, The Netherlands

4 Department of Pharmacy, Princess Máxima Center for Pediatric Oncology, Utrecht, The Netherlands

5 Department of Infectious Diseases, Wilhelmina Children's Hospital, University Medical Center Utrecht, Utrecht, The Netherlands

6 Department of Infectious Diseases, Princess Máxima Center for Pediatric Oncology, Utrecht, The Netherlands

7 Center of Expertise in Mycology Radboudumc/CWZ, Nijmegen, The Netherlands posaconazole, and voriconazole are recommended for managing invasive aspergillosis [1] and fluconazole and voriconazole are recommended for managing invasive candidiasis [2, 3].

Understanding the pharmacokinetics (PK) of these triazoles in pediatric patients is crucial to provide the most beneficial treatment. While the PK of triazoles is extensively studied in adult populations, knowledge on the PK of triazoles in pediatric patients is limited. Pediatric dose recommendations of triazoles have either been adjusted several times in the past years (i.e., voriconazole) or have been reported in the literature to a limited extent (i.e., isavuconazole, itraconazole, and posaconazole). This review provides an overview of current knowledge on the PK of the triazoles fluconazole, itraconazole, voriconazole, posaconazole, and isavuconazole in pediatric populations and summarizes factors that have to be taken into account to select the optimal dose.

\section{Search Methodology}

Relevant articles that describe the PK of triazoles in pediatric patients were searched until 26 November, 2020 using the databases PubMed and Embase. A detailed description of the literature search strategy is given in the Electronic Supplementary Material. Conference abstracts and unpublished 


\section{Key Points}

Fluconazole pharmacokinetics is extensively studied in the neonatal population but requires more extensive research in children and adolescents. Voriconazole pharmacokinetics is extensively studied in children and adolescents and could benefit from more information in the critically ill neonatal and pediatric population despite its limited clinical use in these populations.

Isavuconazole, posaconazole, and itraconazole pharmacokinetics are studied to a limited extend in pediatric populations. To our opinion, specifically isavuconazole and posaconazole pharmacokinetics need to be investigated, as these drugs are frequently used in the hematooncology setting.

For all triazole agents, there is very limited knowledge on pharmacokinetics in critically ill patients who are likely to have altered pharmacokinetics. In addition, information on the impact of dialysis, extracorporeal membrane oxygenation as well as renal or hepatic impairment is lacking in most cases and should warrant further exploration.

data from conference proceedings were not included in this review.

The order of appearance of each triazole in this article is in the order of appearances of market introduction. This emphasizes the need for more prompt action to investigate the PK for the newest released drugs and to learn from pitfalls from the past. After providing a general introduction on pharmacology for all triazoles, a general introduction of each triazole will be given including indications and dose recommendations from the current labels and guidelines. Next, triazole absorption, distribution, metabolism, and elimination characteristics in adults will be described followed by relevant details on pediatric PK for both non-compartmental analyses (NCA) and population PK analyses.

\section{Mechanism of Action: Pharmacology}

All triazoles block the conversion of lanosterol to ergosterol through inhibition of the enzyme lanosterol $14 \alpha$-demethylase (cytochrome P450 [CYP] 51). The depletion of ergosterol and accumulation of its toxic sterol precursors weaken the cell membrane structure and lead to cell membrane dysfunction [4-8]. Next to their fungal pharmacological target, triazoles are substrates and/or inhibitors of the human equivalent CYP enzyme system [4-8]. An overview of the metabolic routes and enzyme affinities of triazoles is provided in Table 1.

\section{Fluconazole}

The US Food and Drug Administration (FDA) approval of fluconazole in adult patients was received in 1990 and fluconazole is licensed in individual European member states since 1988 [4, 9]. Fluconazole formulations include a solution for intravenous infusion and capsules, tablets, syrup, and powder for suspension for oral administration [9]. Currently, fluconazole is approved in pediatric patients aged 0-17 years for the treatment of mucosal candidiasis, for invasive candidiasis and cryptococcal meningitis, for prophylaxis and treatment of Candida infections in immunocompromised patients, and for prophylaxis (of relapse) and treatment of cryptococcal meningitis in high-risk patients $[9,10]$. The fluconazole dosing recommendations in the European and American labels, the European Society of

Table 1 An overview of the metabolic routes and enzyme inhibition of triazoles

\begin{tabular}{|c|c|c|c|c|c|}
\hline & Fluconazole $^{\mathrm{a}}$ & Isavuconazole & Itraconazole & Posaconazole & Voriconazole \\
\hline CYP2C9 & Moderate inhibitor $[4,82]$ & & & & Substrate $^{\mathrm{b}} /$ weak inhibitor $[5,82]$ \\
\hline CYP2C19 & Strong inhibitor $[4,82]$ & & & & $\begin{array}{l}\text { Moderate substrate/weak inhibitor } \\
{[5,82]}\end{array}$ \\
\hline CYP3A4/A5 & Moderate inhibitor $[4,82]$ & $\begin{array}{l}\text { Substrate } / \text { moder- } \\
\text { ate inhibitor [7] }\end{array}$ & $\begin{array}{l}\text { Substrate } / \text { strong } \\
\text { inhibitor [6, } \\
\text { 82] }\end{array}$ & Strong inhibitor $[8,82]$ & Substrate ${ }^{\mathrm{b}} /$ strong inhibitor $[5,82]$ \\
\hline UGT & & Substrate $^{\mathrm{b}}[7]$ & & Substrate/inhibitor $^{\mathrm{b}}[83]$ & \\
\hline P-gp & & Mild inhibitor [7] & Inhibitor $^{\mathrm{b}}[6,82]$ & Substrate/inhibitor $^{\mathrm{b}}[83]$ & \\
\hline
\end{tabular}

CYP cytochrome P450, FDA US Food and Drug Administration, $P$ - $g p$ P-glycoprotein, $U G T$ uridine diphosphate glucuronosyltransferase

${ }^{\mathrm{a}}$ Renal excretion

${ }^{\mathrm{b}}$ Substrate sensitivity/inhibition mentioned in the FDA label and/or FDA drug interaction and labeling list, but the potency of sensitivity/inhibition is not mentioned and therefore not further specified in this table 


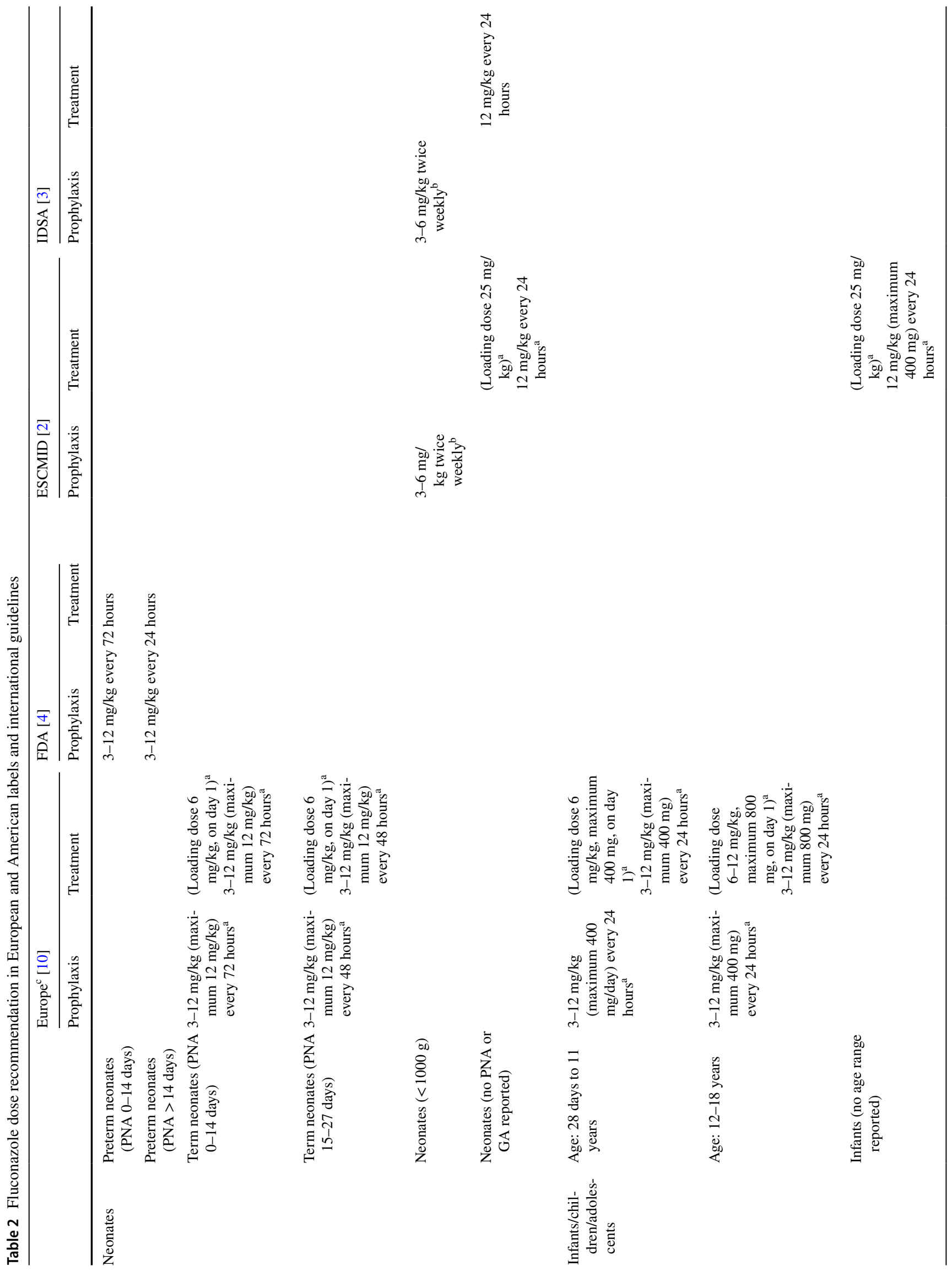




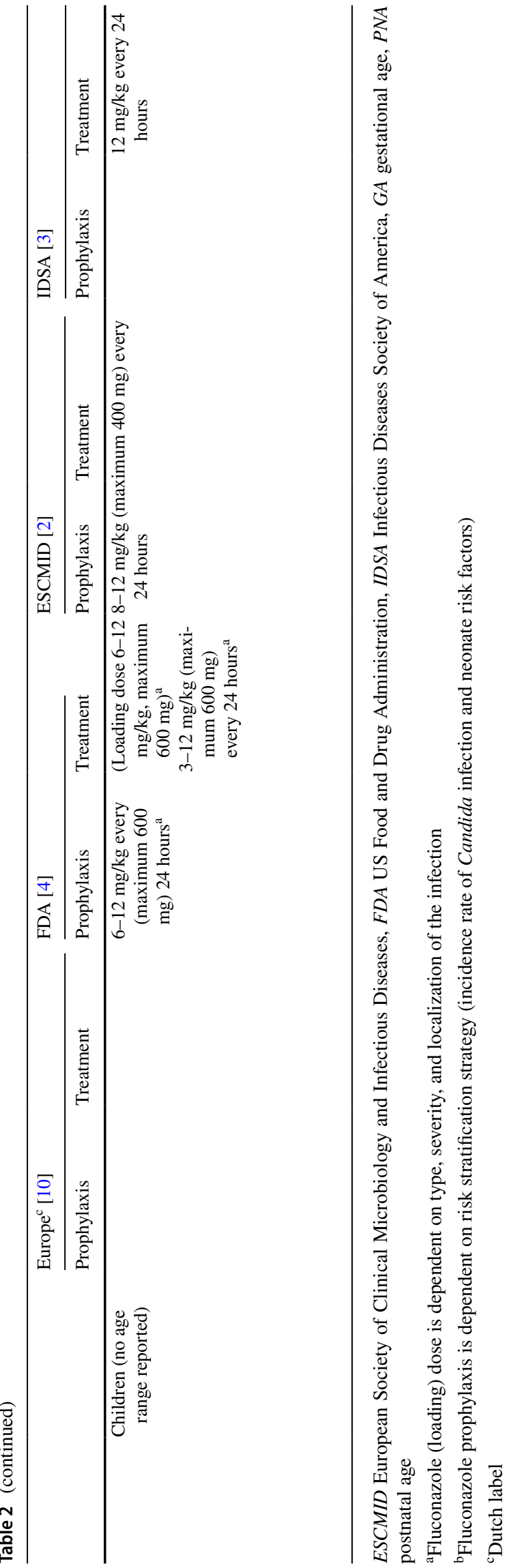

Clinical Microbiology and Infectious Diseases (ESCMID), and the Infectious Diseases Society of America guidelines are given in Table 2. The recommendations in the labels are different from the international guidelines, but also differ slightly between these international guidelines. Consensus between labels and guidelines is necessary to provide good clinical practice.

Fluconazole is characterized by a bioavailability $(F)$ of $90 \%$ in adults, which makes intravenous and different oral formulations interchangeable. Absorption of fluconazole is not affected by food intake. The volume of distribution $\left(V_{\mathrm{d}}\right)$ of fluconazole is approximately $0.7 \mathrm{~L} / \mathrm{kg}$ [4]. Fluconazole shows good penetration in a variety of body fluids and tissues, such as cerebrospinal fluid, sputum, saliva, urine, and skin [11]. The affinity of fluconazole for plasma proteins is low (10-12\%). Fluconazole is minimally metabolized $(\sim 10 \%)$ and the route of elimination is primarily $(\sim 80 \%)$ unchanged via renal excretion. Mean clearance (CL) of fluconazole is around $0.0138 \mathrm{~L} / \mathrm{h} / \mathrm{kg}$ in adults [4].

\subsection{Non-Compartmental Analysis of Fluconazole PK in Pediatric Patients}

Six studies described NCA of fluconazole PK in pediatric patients [12-17]. One study was performed in neonates [12] and five studies were performed in infants and children [13-17]. A detailed overview of the dosing regimens and fluconazole pharmacokinetic results is given in Table 3 . The neonatal study included 12 premature neonates aged $<24 \mathrm{~h}$ after birth receiving fluconazole intravenously in a dose of $6 \mathrm{mg} / \mathrm{kg}$ with a dose interval of $72 \mathrm{~h}$ [12]. The five studies in preterm and term infants and children included patients with hematological or non-hematological malignancies, congenital disease, neoplastic disease, human immunodeficiency virus (HIV), or patients with and without peritoneal dialysis (PD) after open heart surgery with an age range of 2 weeks to 16 years [13-17]. Doses of fluconazole were 2-8 $\mathrm{mg} / \mathrm{kg}$ per day administered either intravenously or as an oral suspension [13-17].

Although three out of these six studies included fluconazole as an oral formulation, none of them described the relative or absolute $F$ of fluconazole $[13,15,16]$. During the first 2 weeks after birth, the $V_{\mathrm{d}}$ of fluconazole in premature neonates almost doubled and CL increased more than two times [12]. After 2 weeks of life, the $V_{\mathrm{d}}$ of premature neonates was found to be higher compared with children $[12,14,15,17]$. After this period, the $V_{\mathrm{d}}$ decreased [14, $15,17]$ and comparable values to adults were reported in children aged $\geq 12$ years. [4, 15] These data suggest that premature neonates aged $\geq 2$ weeks need adequate loading doses compared to premature neonates straight after birth and that children aged $<12$ years need adequate loading doses compared to older children and adults. The higher $V_{\mathrm{d}}$ 
of fluconazole in premature neonates vs children and adults might be explained by the characteristics of fluconazole and body composition of neonates. Fluconazole is a hydrophilic compound, and neonates tend to have a higher water: fat ratio and as such a higher $V_{\mathrm{d}}$ [18]. The increasing fluconazole CL observed in neonates during the first 2 weeks of life might be explained by the maturation of the kidney function during this period [19]. Clearance of fluconazole in premature neonates seemed to reach the same range as children 2 weeks after birth [14, 17] but was still higher compared with adults [4]. A higher maintenance dose or shorter dosing intervals might be needed in premature neonates, infants, and children compared with adults. Contrary to these studies, one study in premature infants aged $<3$ months reported comparable CL to adults, after a single dose of fluconazole [15]. Three studies described exposure of fluconazole after different dosing regimens and found a dose-proportional increase in exposure [15-17]. In patients with PD, no statistical differences in $\mathrm{V}_{\mathrm{d}}$ and $\mathrm{CL}$ were reported compared to non-PD children with mild renal dysfunction. However, the elimination half-life of fluconazole was significantly longer in PD patients. This points towards the need for a lower maintenance dose or a longer dosing interval in this pediatric PD population [14]. To our knowledge, no other disease variables, such as HIV, have been found to alter the exposure of fluconazole [15-17].

\subsection{Population Pharmacokinetic Analysis of Fluconazole in Pediatric Patients}

Nine population pharmacokinetic studies were conducted that included either neonatal patients [20,21], a mixed patient population of neonates and infants [22-27], or children and adolescents aged 3 days to 15.9 years [28]. One of these studies pooled data from three previously reported studies [26]. A detailed overview of the dosing regimens and fluconazole pharmacokinetic results is given in Table 4. The following patient groups were included in these studies: preterm and term patients at risk for IFD, patients with suspected or documented oral or invasive Candida infections, patients supported with extracorporeal membrane oxygenation (ECMO), or immunocompromised hematooncology patients. Eight studies described fluconazole PK in a one-compartment model [20-27], of which two studies included first-order absorption in the pharmacokinetic model $[20,21]$. One study described fluconazole data best with a two-compartment model and first-order absorption [28]. The pharmacokinetic models and tested covariates are summarized in Table 5.

Overall, population pharmacokinetic studies showed that the relative $F$ from 90.9 to $100 \%[20,21,28]$ in neonates, infants, and children was excellent, and was comparable to a $F$ of $>90 \%$ in adults [4]. The rate of oral bioavailability $\left(K_{\mathrm{a}}\right)$ was from 0.538 to $3.76 \mathrm{~h}^{-1}[20,21,28]$. It is difficult to compare values of $V_{\mathrm{d}}$ and CL between fluconazole population pharmacokinetic studies directly, as a variety of covariates were included on $V_{\mathrm{d}}$ and CL. Allometrically scaled bodyweight with fixed [20, 21, 23] and/or estimated [20] exponents was added on either $V_{\mathrm{d}}[20,21,23]$ and/or CL [20, 21, 23]. Age (inversely related) [27], ECMO [25], a coefficient for ECMO [26] and/or linearly scaled bodyweight $[26,28]$ were included as covariates on $V_{\mathrm{d}}$. Covariates as linearly scaled bodyweight [26], body surface area [28], serum creatinine [24, 25], and exponents for estimated glomerular filtration (estimated) [20], serum creatinine [21, 23, 26], postmenstrual age (PMA) as a function of gestational age (GA) and postnatal age (PNA), [21] gestational age at birth (BGA) [23] and/or PNA [23], were included on CL. Serum creatinine was inversely related to CL [21, 23-26]. In one study, it was not clear if postmenstrual age was included as a covariate on fluconazole CL in the final model [22]. Another study reported that bodyweight influenced fluconazole CL but did not report the covariate equation [22]. Three studies used a linear regression analysis to test covariates [24, 25, 28]. One study concluded that fluconazole CL in premature neonates was low at birth and doubled within the first month after birth, but did not report on changes in fluconazole $V_{\mathrm{d}}$ [23]. This conclusion is slightly different from a previous NCA report, which reported a more than two-fold increase in CL during the first 2 weeks of life. Another study included both ECMO and non-ECMO patients and reported a significantly higher $V_{\mathrm{d}}$ but similar CL in pediatric ECMO patients compared with non-ECMO patients [26]. This higher $V_{\mathrm{d}}$ is likely due to the hydrophilic nature of fluconazole and the large circulating volume of ECMO procedures [29]. These population pharmacokinetic results point toward the need for an adequate loading dose of fluconazole in pediatric ECMO patients.

\subsection{Physiologically Based PK of Fluconazole}

Two studies have obtained interesting pharmacokinetic information with physiologically based pharmacokinetic models and assessed fluconazole dosing by predicting either cerebrospinal fluid exposure or the influence of ECMO [30, 31]. Data from plasma samples of 166 infants $(<750 \mathrm{~g})$ with a median PNA of 21 days (range 3-93 days) and cerebrospinal fluid samples of 22 infants with a median PNA of 28 days (range 24-33 days) showed fluconazole exposure in the central nervous system, with a central nervous systemto-plasma ratio of $\sim 1$ [30]. In the second study, the edema disease state of ECMO patients was added to the model and the authors suggested that edema contributes to lower fluconazole exposure [31] 


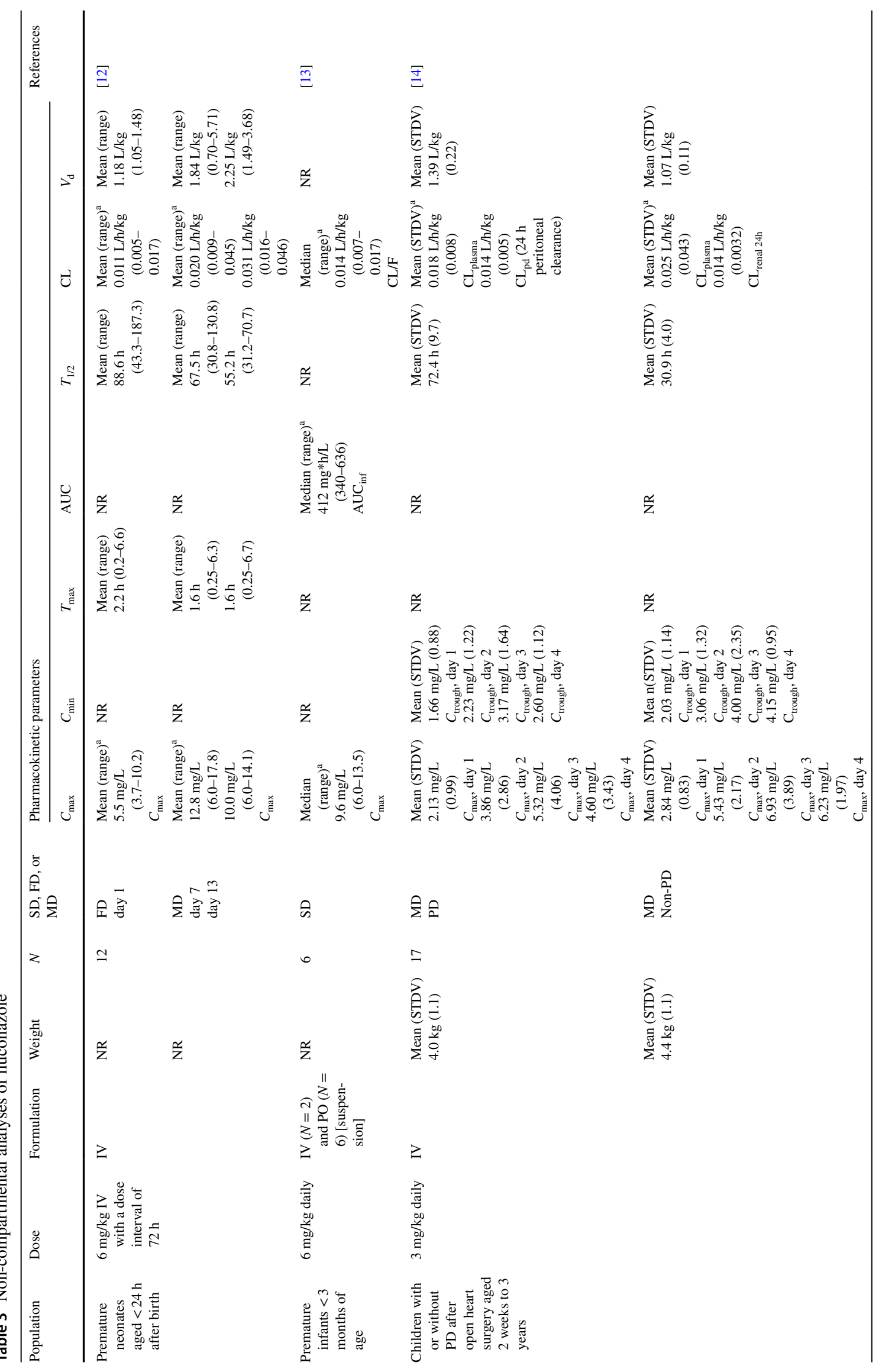




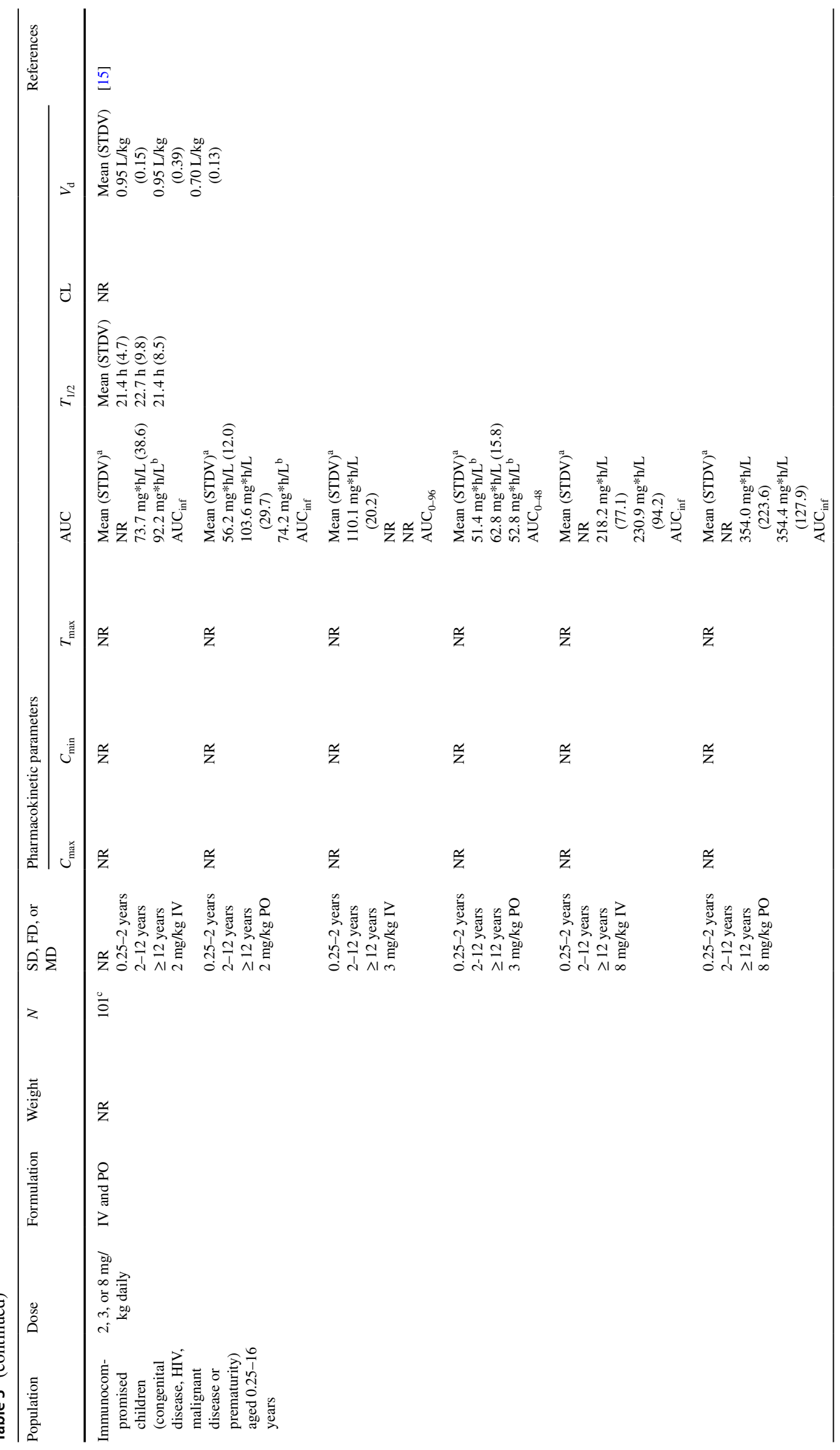




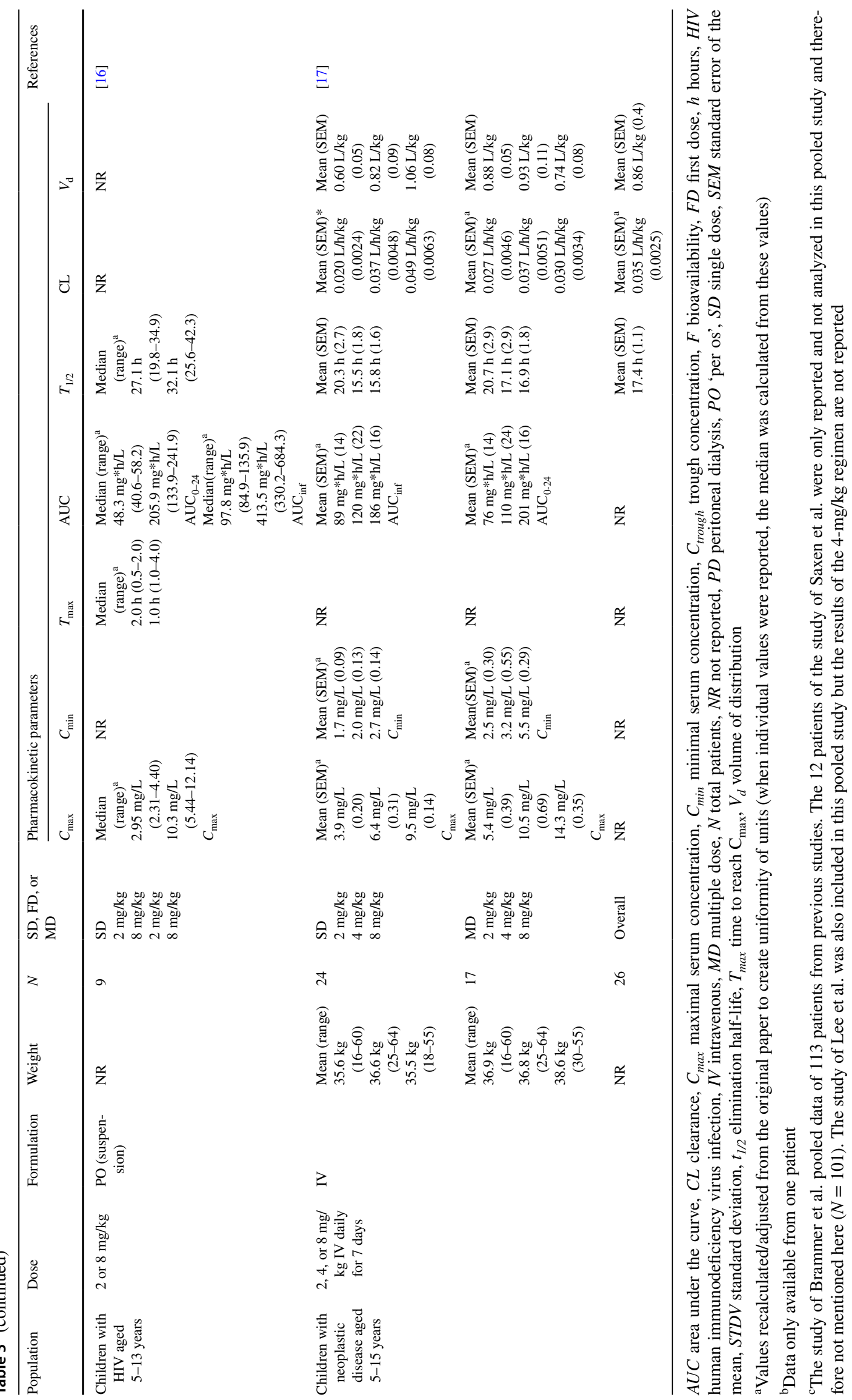




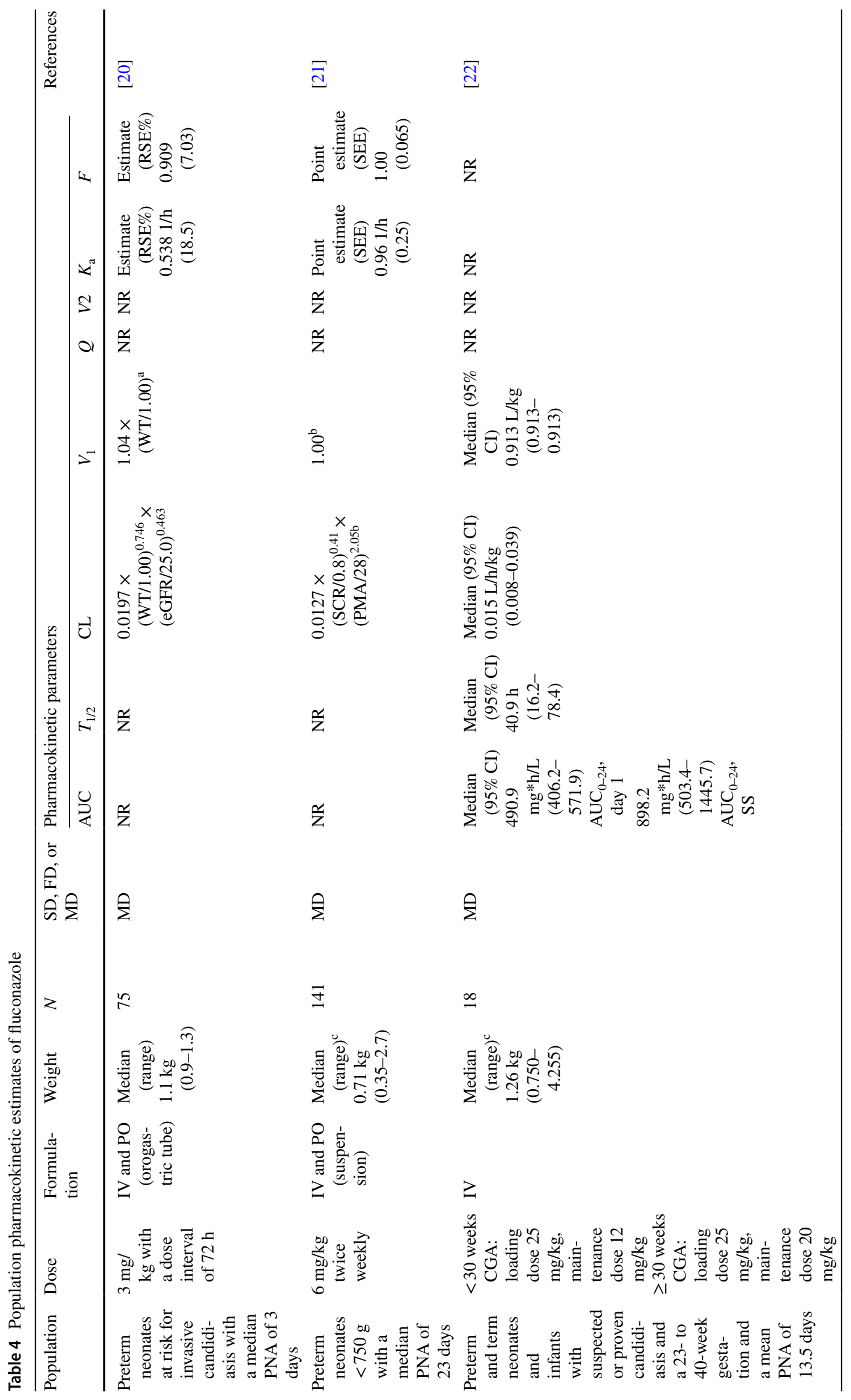




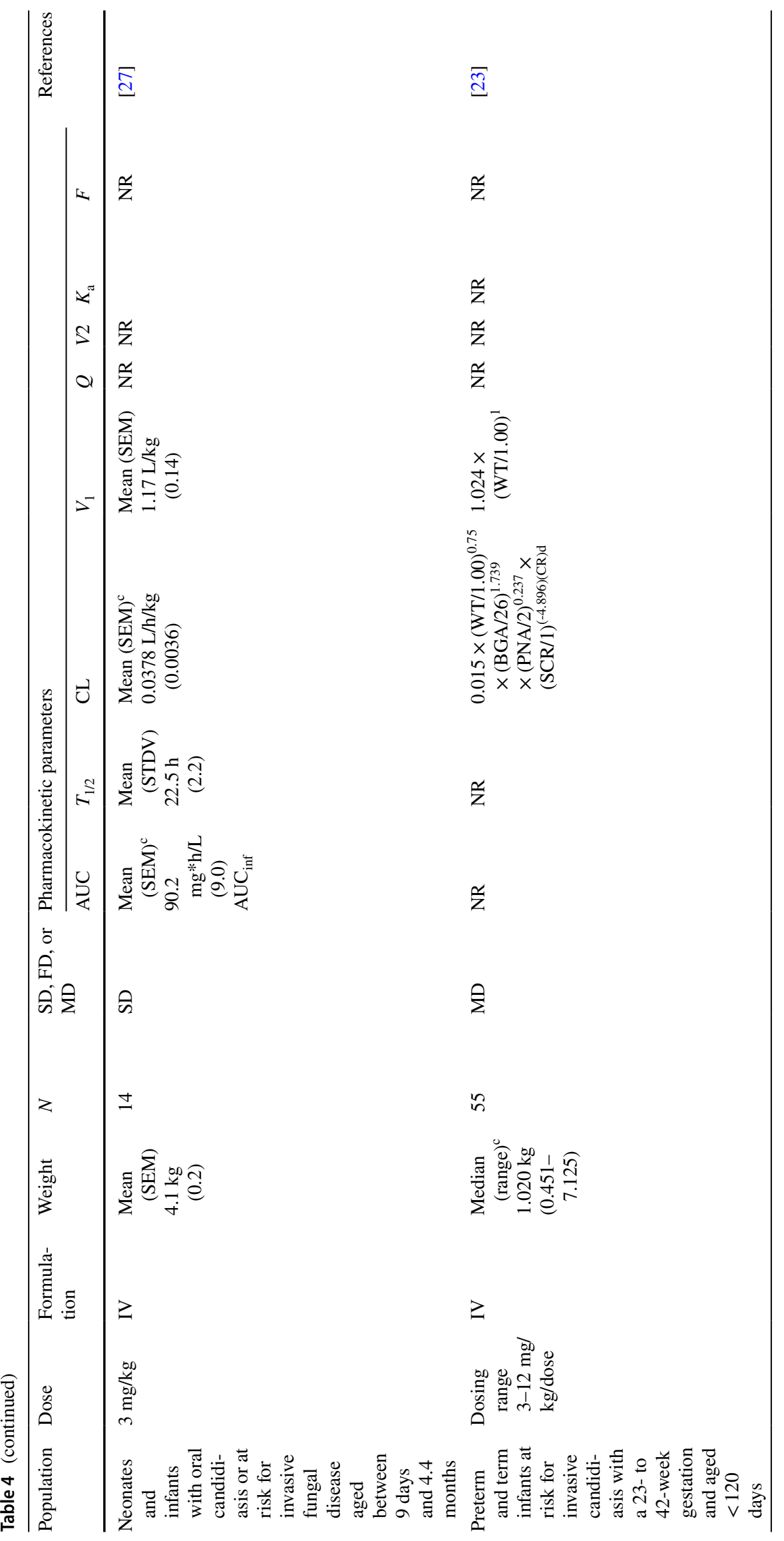

$\Delta$ Adis 


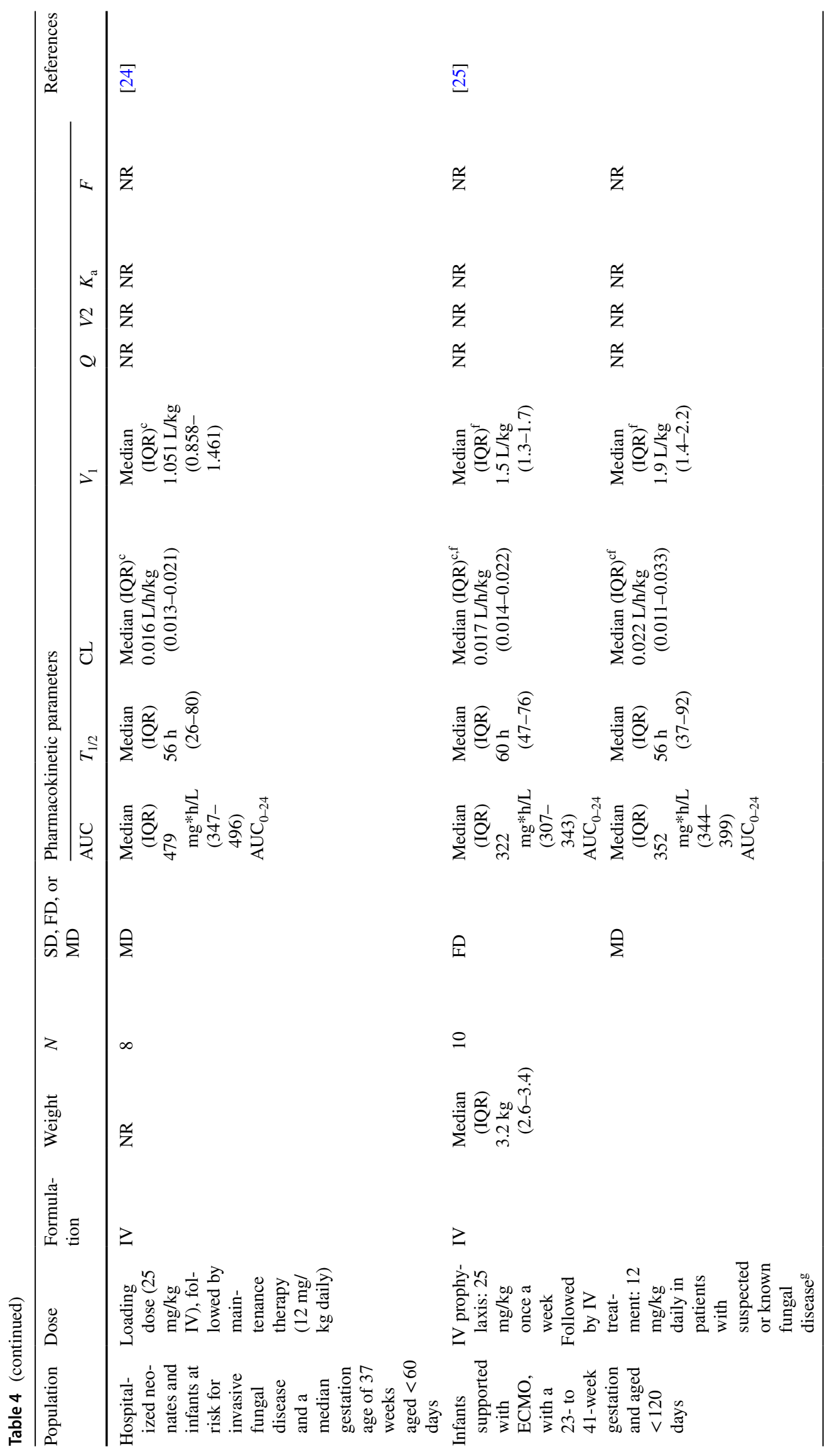




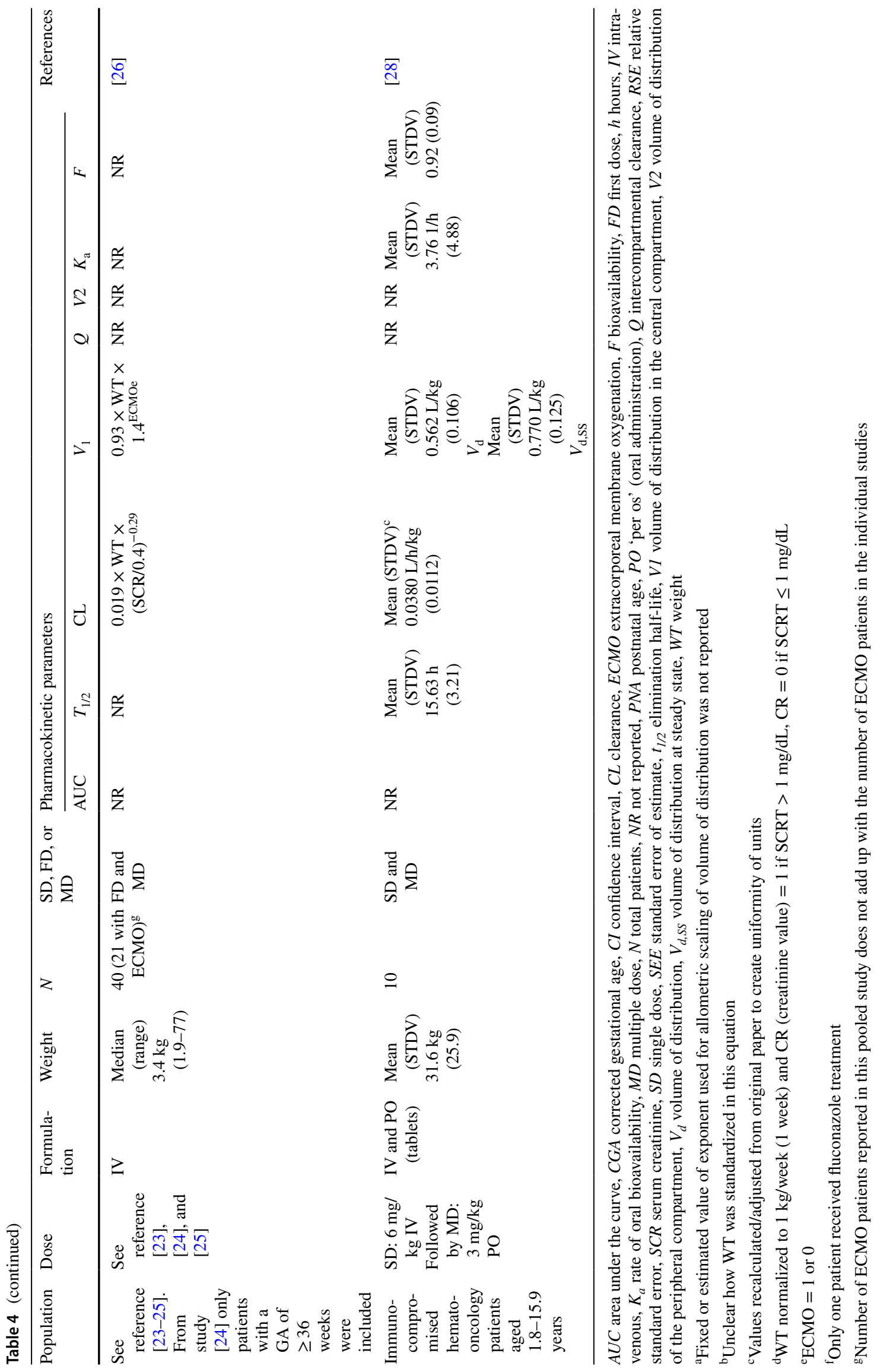




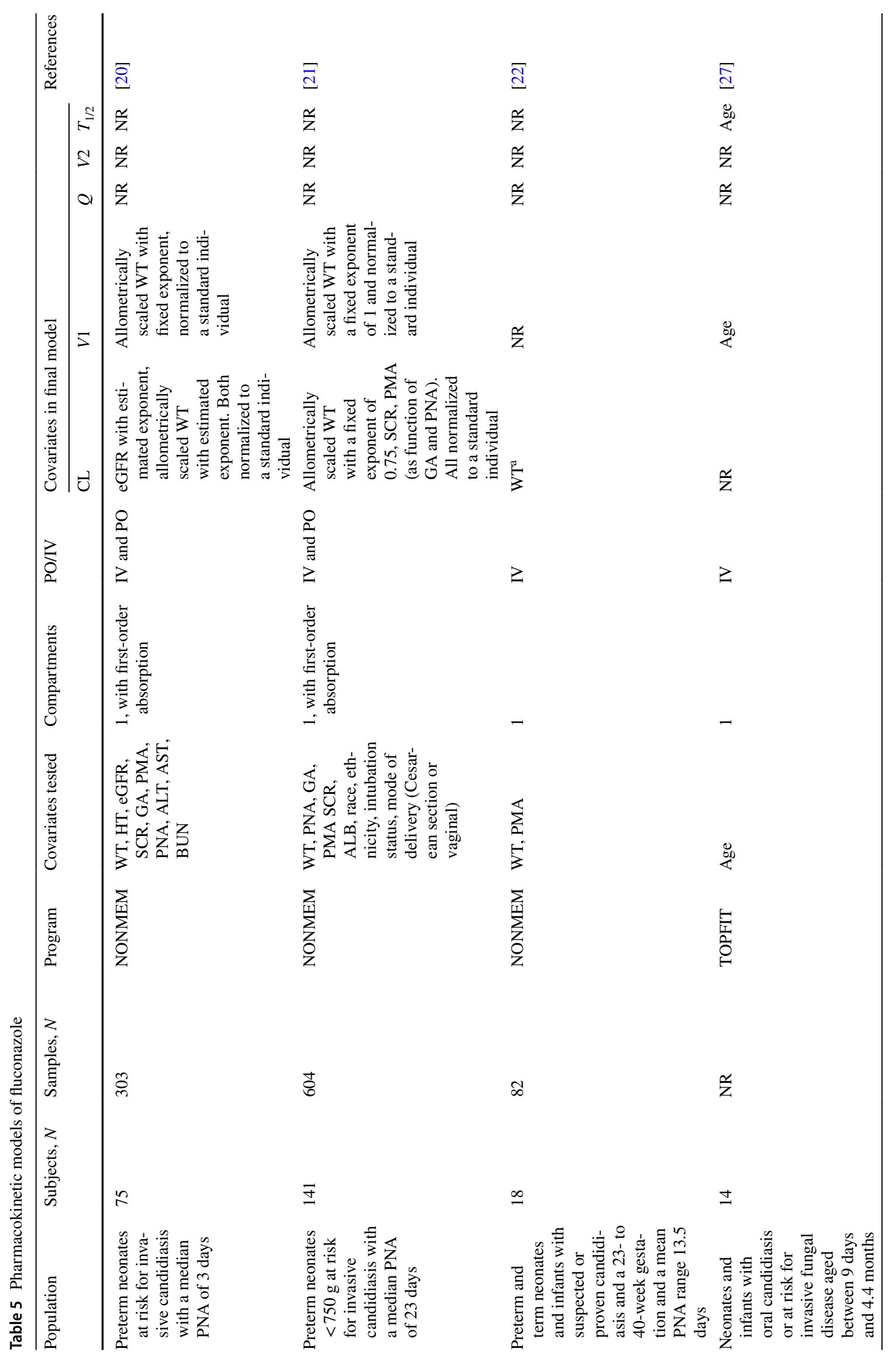




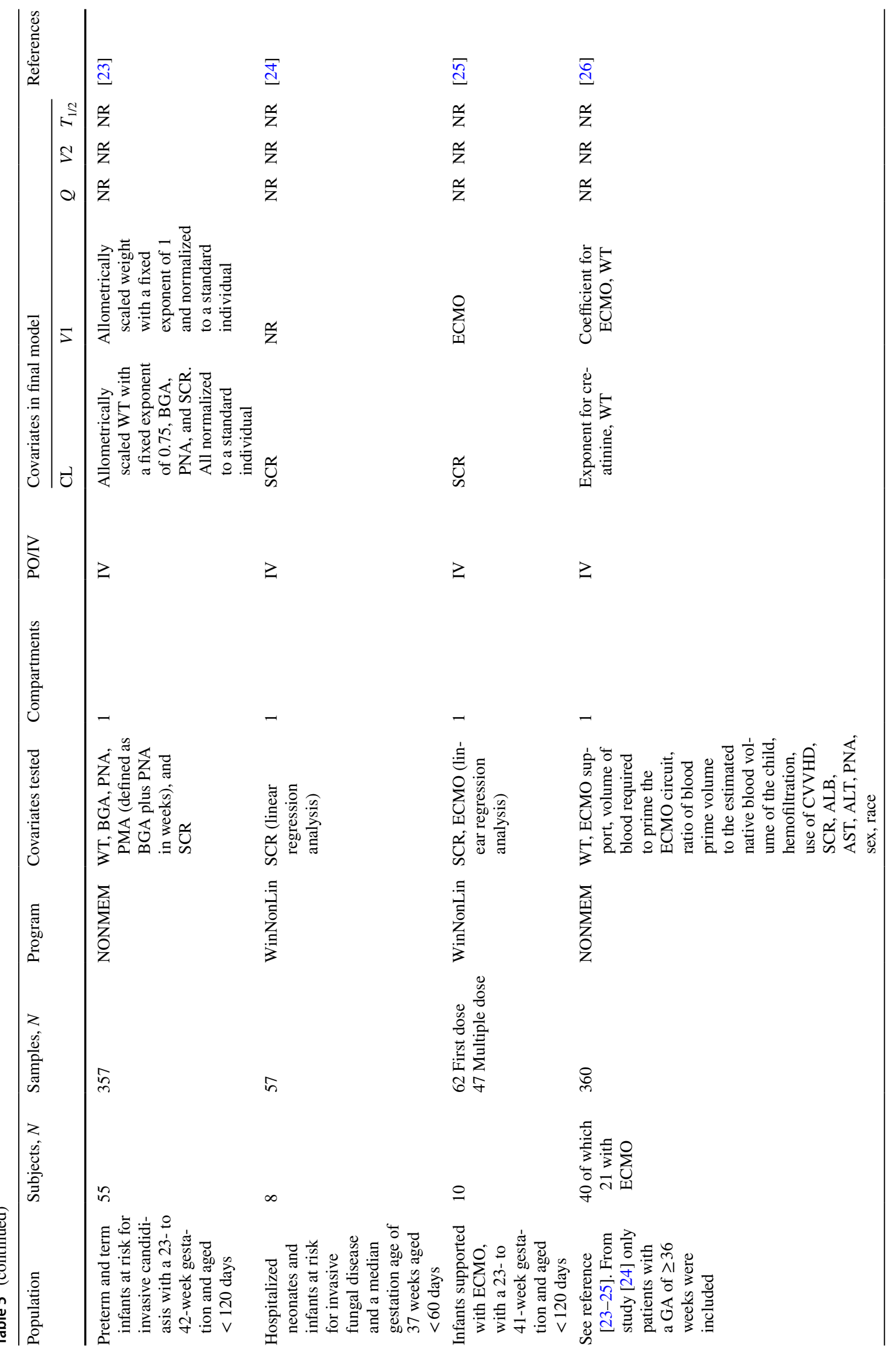




\subsection{Summary of Findings and Recommendations}

Pharmacokinetic data of fluconazole in neonates and infants are abundant, and pharmacokinetic data of fluconazole in children and adolescents are scarce. Research topics should include the $F$ of all different oral fluconazole formulations and full pharmacokinetic investigations in children and adolescents. Special patient populations such as critically ill pediatric patients with renal impairment or other renal replacement therapy and solid organ transplant recipients should be further investigated. Additionally, the influence of the disease state of patients, such as excess fluid retention, on fluconazole PK might be interesting to further explore.

The relative $F$ of fluconazole in pediatric patients is comparable to the $F$ described in adults, which suggests that different formulations of fluconazole are interchangeable in pediatric patients. Most of these studies included the suspension as oral formulation, data on $F$ of other oral formulations are very limited in pediatric patients.

Non-compartmental analyses report a higher $V_{\mathrm{d}}$ in preterm neonates compared with children and adults. These results suggest that adequate loading doses are needed. In preterm neonates, the fluconazole $\mathrm{CL}$ increases during the first 2 weeks after birth. The CL after 2 weeks of birth is comparable to $\mathrm{CL}$ in children but higher as compared to $\mathrm{CL}$ in adults. These results imply that higher maintenance doses or shorter dosing intervals are needed in preterm neonates and children. Non-compartmental analyses in pediatric PD patients report a significantly increased elimination half-life for fluconazole and these data suggest a lower maintenance dose or a longer dosing interval in this pediatric population.

Population PK studies report that allometrically scaled bodyweight and ECMO are significant covariates on $V_{\mathrm{d}}$. As a consequence, pediatric patients receiving ECMO might need higher loading doses. Allometrically scaled bodyweight, serum creatinine (inversely related), and either PMA (as a function of GA and PNA), or GA and PNA are significant covariates on CL. Dose adjustments based on serum creatinine, GA, and PNA might be taken into account to optimize fluconazole use. A standardized method to report both allometric scaling and maturation would be useful to compare pharmacokinetic results from different studies and populations.

Dose recommendations for fluconazole are inconsistent between the labels and the ESCMID and Infectious Diseases Society of America guidelines. As outlined previously by others [22], agreement between labels and international guidelines is necessary for clinical practice. Currently, there is no possibility to translate expert consensus from guidelines to an updated product information sheet. A reference in the summary of product characteristics to relevant guidelines would be an option to cover this. However, the legal background to make it possible for authorities and the 
pharmaceutical industry to request and update their product information will be tremendously challenging.

\section{Itraconazole}

Itraconazole was approved for adult patients in 1992 by the FDA [6] and itraconazole has been licensed in individual European member states. The oral capsules and oral solution are widely available in contrast to the intravenous formulations [32]. Itraconazole is not approved in pediatric patients aged $<18$ years $[6,33]$. However, the pediatric ESCMIDECMM guideline for invasive aspergillosis and the pediatric ESCMID guideline for invasive candidiasis recommend a dose of $2.5 \mathrm{mg} / \mathrm{kg}$ twice daily of the oral solution for the purpose of mold and yeast active prophylaxis in children aged 2-18 years $[1,2]$. For treatment of a proven or probable invasive aspergillosis, itraconazole is recommended in a loading dose of $5 \mathrm{mg} / \mathrm{kg}$ twice daily of the oral solution on day 1 , followed by $2.5 \mathrm{mg} / \mathrm{kg}$ twice daily in patients aged 2-18 years [1].

In adults, itraconazole has a variable $F$ with an absolute oral $F$ of the oral solution of 55\% [6]. The $F$ of the oral solution is $\sim 30 \%$ higher compared with the oral capsules [34]. Because of the variable $F$ between formulations, these are not interchangeable. Food intake and $\mathrm{pH}$ fluctuation influence the itraconazole uptake, therefore the oral capsules are advised to be administered in a fed state and the oral solution in a fasted state [35]. The $V_{\mathrm{d}}$ of itraconazole is $>700 \mathrm{~L}$ [6]. Itraconazole penetrates into a variety of body tissues, including the lung, kidney, liver, bone, stomach, spleen, muscle, keratinous tissue, and skin but does not penetrate well into the cerebrospinal fluid [36-38]. Itraconazole has an active metabolite hydroxy-itraconazole with comparable in vitro activity to the parent compound. Both itraconazole (99.8\%) and hydroxy-itraconazole (99.6\%) are highly bound to plasma proteins. Itraconazole is mainly metabolized via CYP3A4 (Table 1). Renal elimination of both itraconazole and hydroxy-itraconazole is $<1 \%$. The inactive metabolites of itraconazole are excreted in the urine (35\%) and feces (54\%). Mean CL of itraconazole in adults is $16.68 \mathrm{~L} / \mathrm{h} \mathrm{[6].}$

\subsection{Non-Compartmental Analysis of Itraconazole PK in Pediatric Patients}

To our knowledge, there are no NCA reports of itraconazole PK described in neonates. Six studies performed NCA of itraconazole in infants, children, and adolescents aged 0.5-17 years at risk of mucosal fungal infection or IFD. A detailed overview of the dosing regimens and itraconazole pharmacokinetic results is given in Table 6. Patients with hematological and non-hematological malignancies, liver transplantation, respiratory tract infections, HIV, cystic fibrosis $(\mathrm{CF})$, other infections/diseases, or undergoing hematopoietic stem cell transplantation (HSCT) were included in these studies. Itraconazole was administered in different oral and intravenous dosing regimens for prophylaxis and/or treatment. Dosages of itraconazole were from 2.5 to $5 \mathrm{mg} / \mathrm{kg}$ once or twice daily, with or without a loading dose of $5 \mathrm{mg} / \mathrm{kg}$ twice daily [39-44].

In five studies, itraconazole was administered as an oral solution [40-44], of which one study also included the intravenous formulation but the authors did not report the $F$ of itraconazole [40]. Three studies stratified pharmacokinetic results of itraconazole by age [39, 42, 43]. A single dose of $2.5 \mathrm{mg} / \mathrm{kg}$ or multiple dosing regimens of $5 \mathrm{mg} / \mathrm{kg}$ once daily or $2.5 \mathrm{mg} / \mathrm{kg}$ twice daily have been investigated in patients aged $0.5-2$ years, $2-5$ years, and/or $>5$ years [39, 42, 43]. Exposures differ widely between groups and studies. Both CL and $V_{\mathrm{d}}$ appear to change strongly within these groups. Interestingly, administration of a $2.5-\mathrm{mg} / \mathrm{kg}$ twice-daily regimen resulted in much higher itraconazole and hydroxy-itraconazole exposures compared with a 5-mg/ $\mathrm{kg}$ once-daily regimen of itraconazole [42-44]. This is possibly owing to saturable absorption. One study in patients undergoing HSCT reported a considerably higher exposure compared with other studies, which is most likely explained by including a loading dose for itraconazole $(5 \mathrm{mg} / \mathrm{kg}$ twice daily on day 1 , followed by $5 \mathrm{mg} / \mathrm{kg}$ once daily) and pharmacokinetic sampling after the third administered dose [40]. Special pediatric populations, such as patients with HIV, showed comparable exposures of itraconazole and hydroxyitraconazole to other populations, while patients with $\mathrm{CF}$ showed a considerably lower exposure after $2.5 \mathrm{mg} / \mathrm{kg}$ of itraconazole twice daily compared with other pediatric populations [41, 44]. Higher dosages than $2.5 \mathrm{mg} / \mathrm{kg}$ twice daily might be needed in pediatric patients with CF.

\subsection{Population Pharmacokinetic Analysis of Itraconazole in Pediatric Patients}

Two population pharmacokinetic studies in pediatric patients have been published $[39,45]$. A detailed description of the dosing regimens and itraconazole pharmacokinetic results is given in Table 7. The pharmacokinetic models and covariates tested are summarized in Table 8 .

In 33 patients at risk for IFD aged $0.5-17$ years, itraconazole was given intravenously as a single $2.5-\mathrm{mg} / \mathrm{kg}$ dose. Underlying diseases included CF, malignancies with febrile neutropenia, respiratory tract infections, or other diseases/ infections. A three-compartment model best fitted the data for itraconazole. All parameter estimates were scaled to a total body weight of $30 \mathrm{~kg}$ [39], but the covariate equations were not reported.

In 49 patients with $\mathrm{CF}$ and undergoing bone marrow transplantation aged $0.4-30$ years, including five adult 


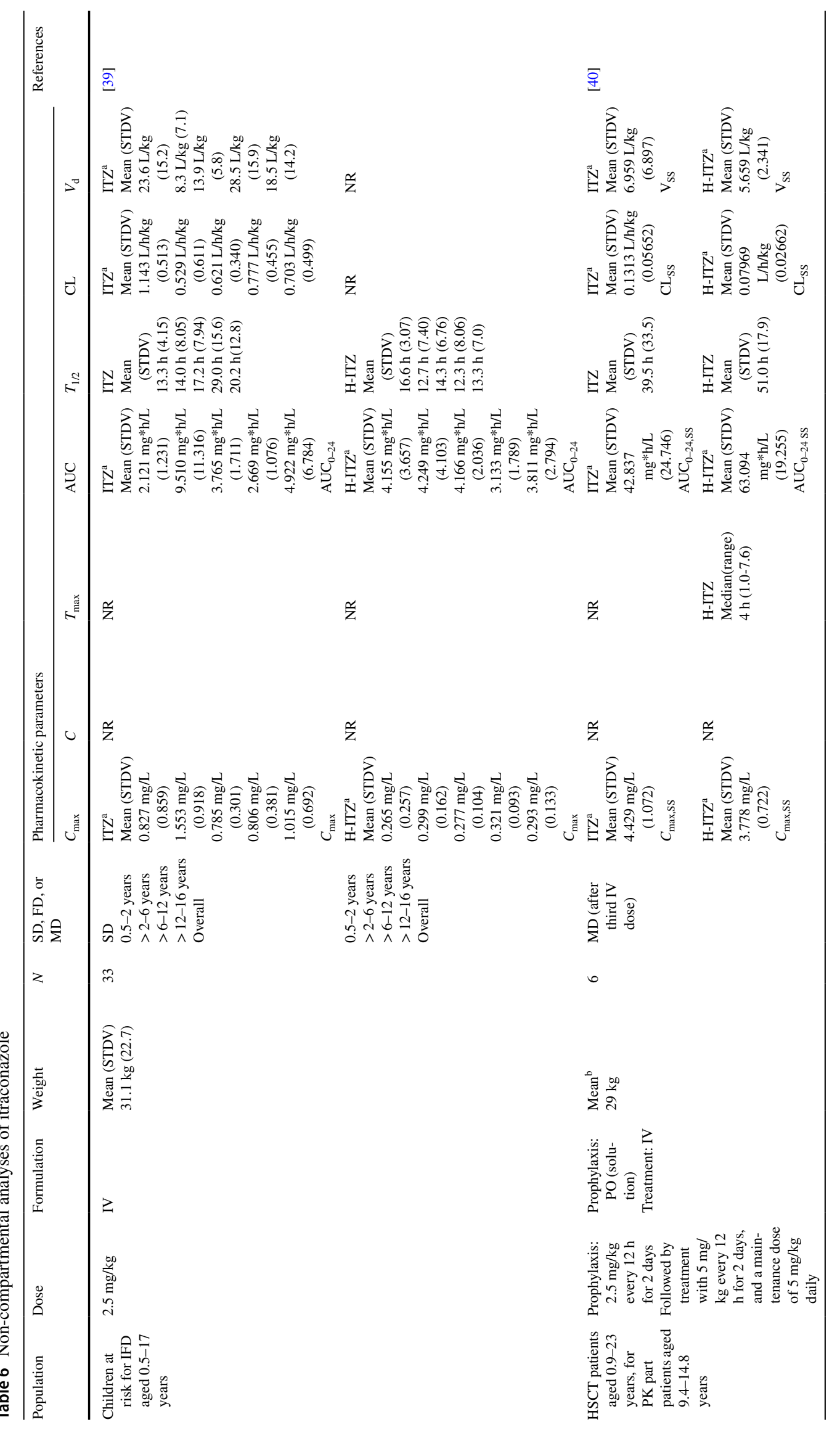




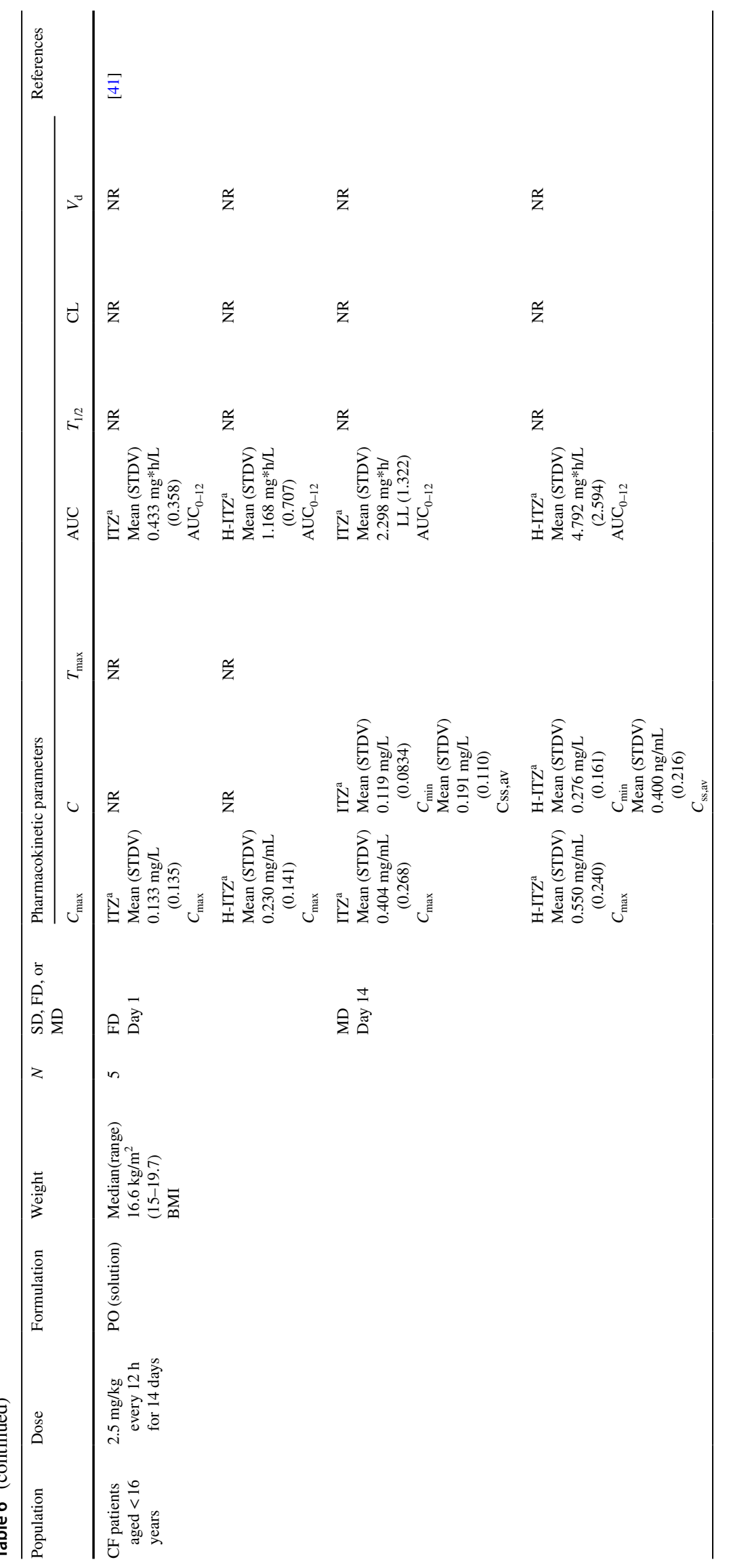

$\triangle$ Adis 


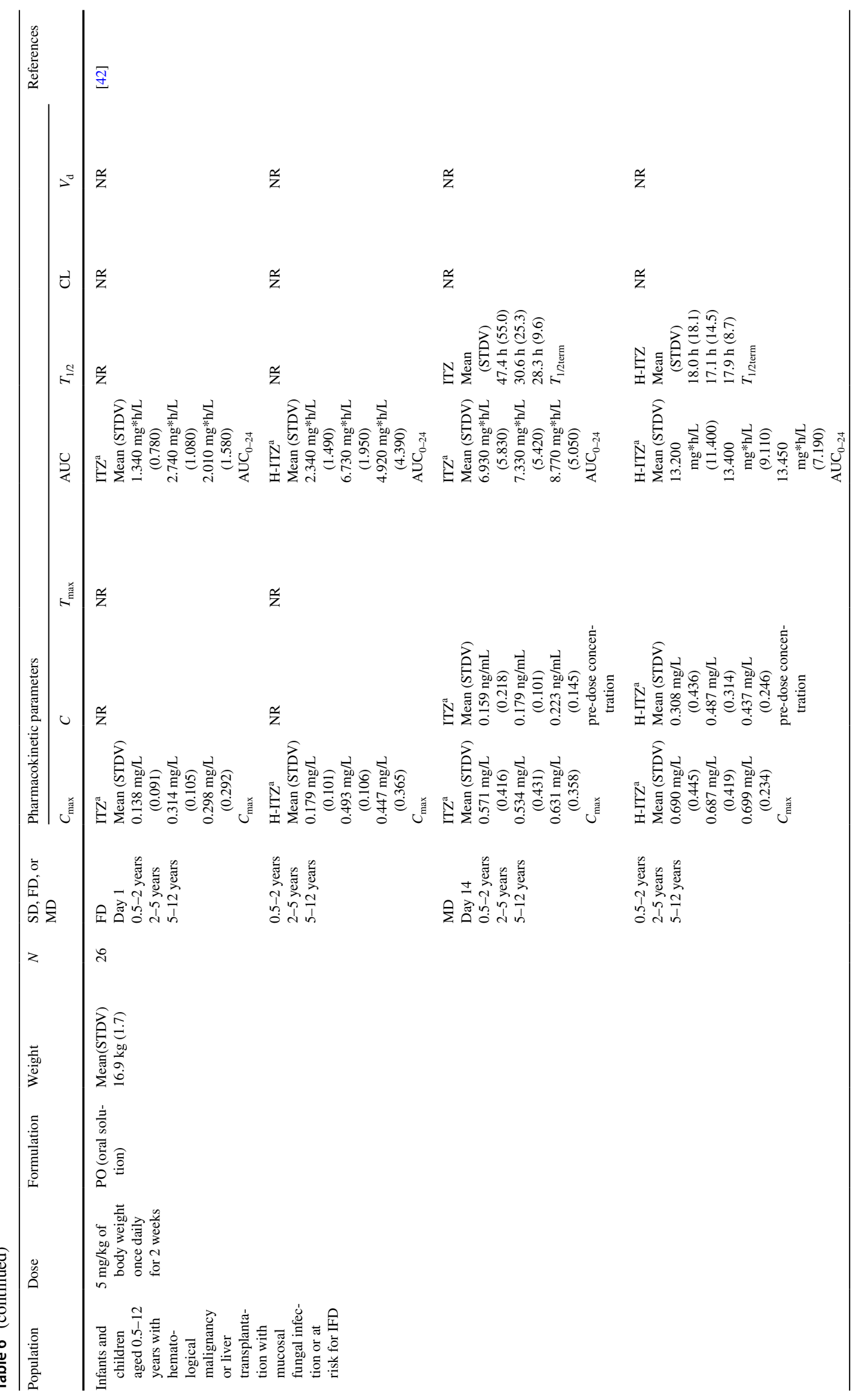


1122

D. Bury et al.

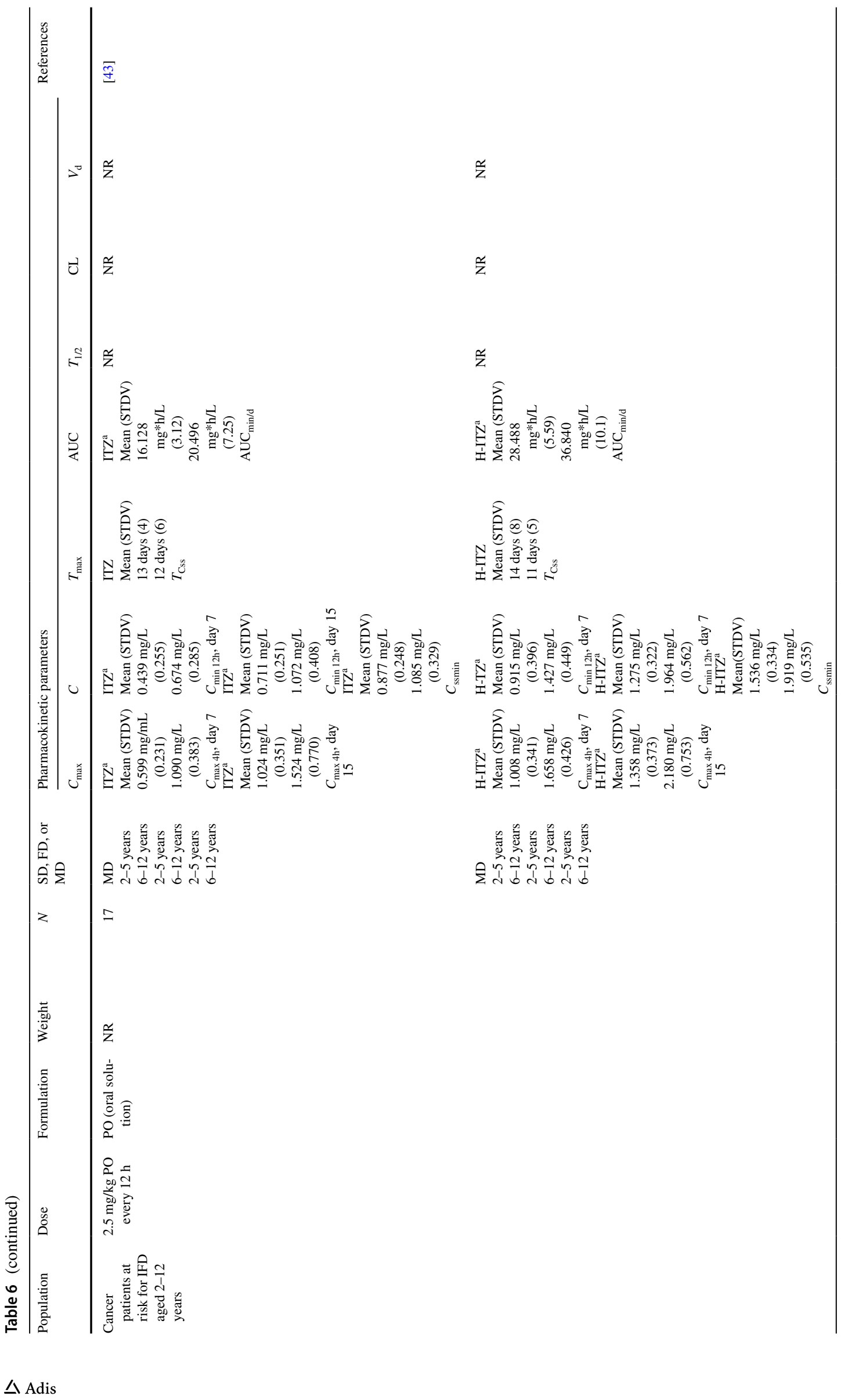




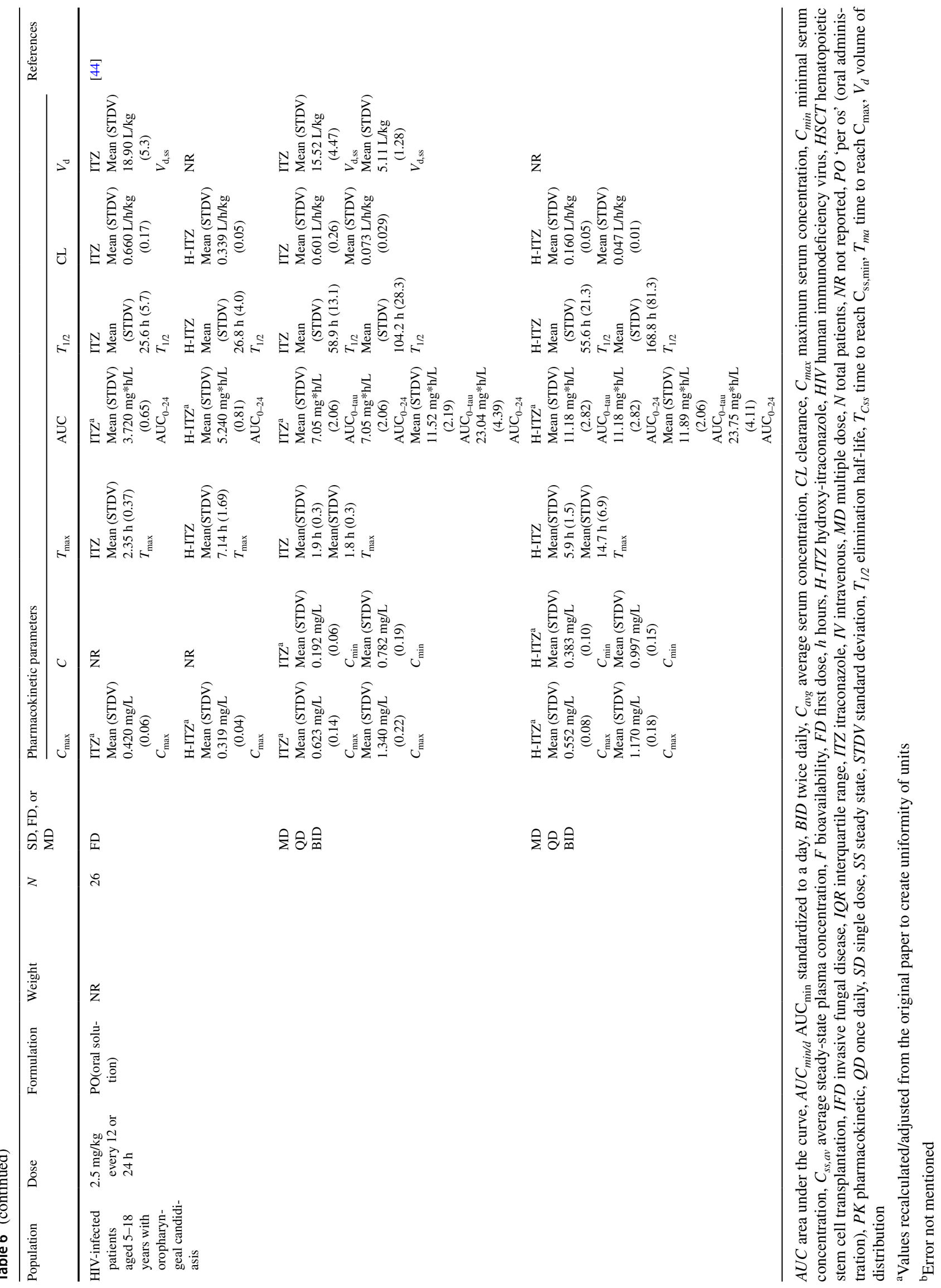




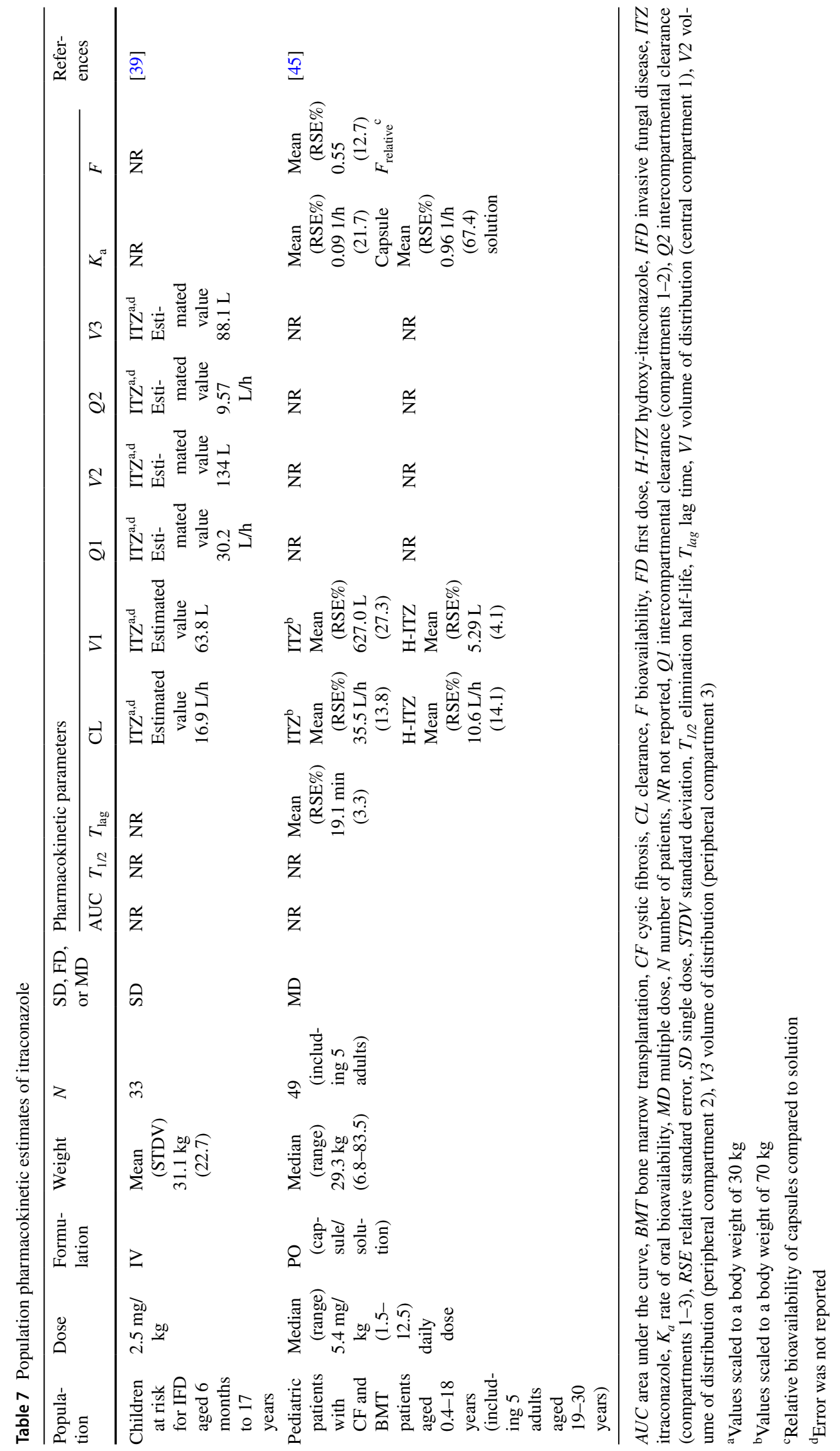




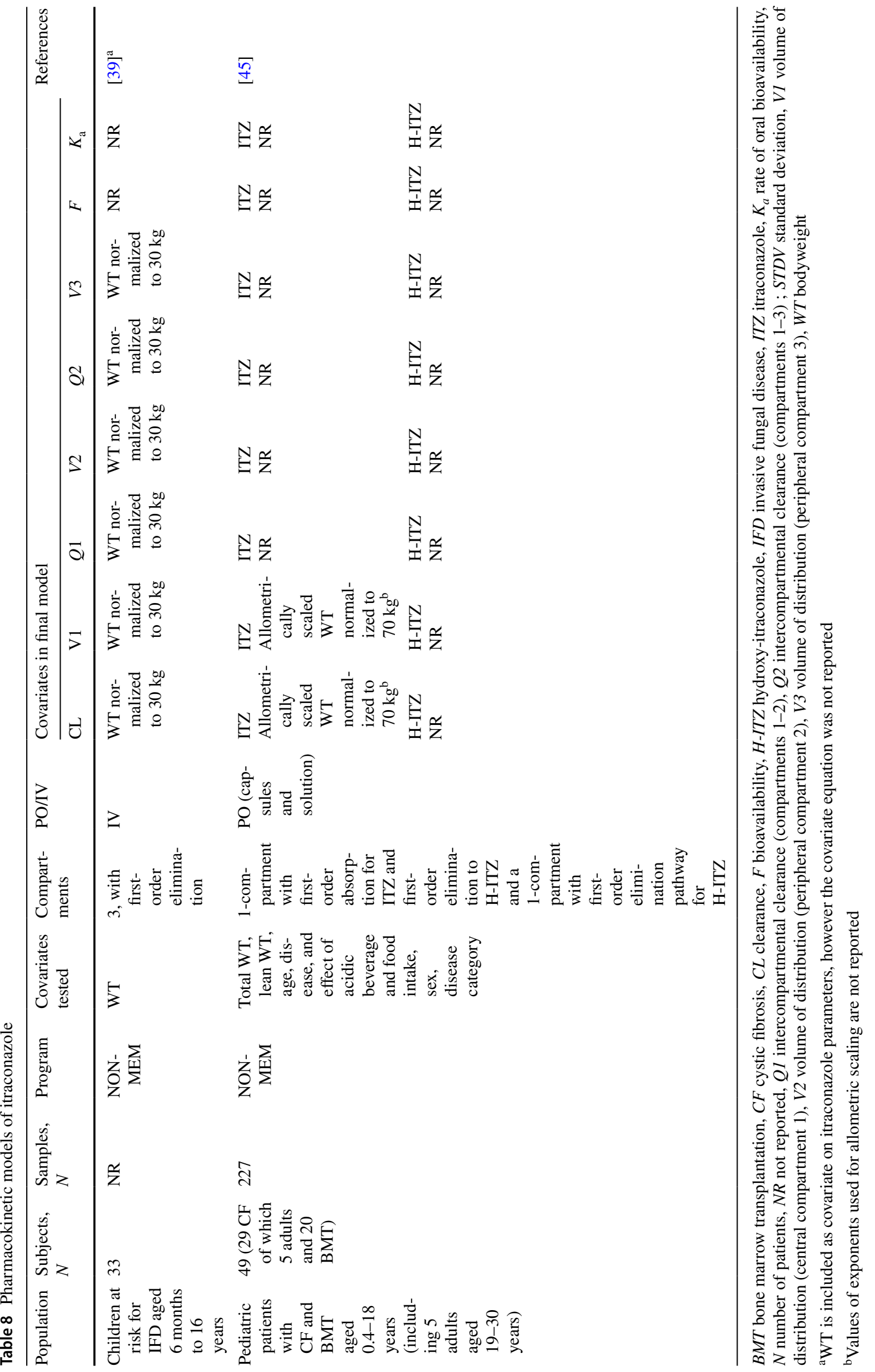


patients, a median itraconazole dose of $5.4 \mathrm{mg} / \mathrm{kg}$ was given orally as capsules or solution. The vast majority of patients received itraconazole in a once-daily regimen. A onecompartment model was used with delayed absorption and included both itraconazole and hydroxy-itraconazole. The $K_{\mathrm{a}}$ for the solution and capsules was $0.96 \mathrm{~h}^{-1}$ and $0.09 \mathrm{~h}^{-1}$, respectively. The relative $F$ of capsules was 0.55 compared to the solution. Clearance and $V_{\mathrm{d}}$ of itraconazole were allometrically scaled to a total body weight of $70 \mathrm{~kg}$ [45]. Values of exponents used for allometric scaling were not reported.

\subsection{Summary of Findings and Recommendations}

Pharmacokinetic studies of itraconazole are limited in pediatric patient populations and are lacking in neonates. Future research should focus on retrieving pharmacokinetic data in these patient populations and should address the $F$ of the different itraconazole formulations.

The itraconazole oral solution is the preferred formulation, as the relative $F$ was $45 \%$ higher compared with itraconazole capsules. Given the unknown absolute $F$ and the difference in $F$ of the oral formulations, dosing of itraconazole and switching between formulations should be accompanied by therapeutic drug monitoring. Furthermore, a twice-daily itraconazole regimen instead of a once-daily regimen is suggested to optimize itraconazole exposure.

Non-compartmental analyses suggest a great extent of variability across different age groups, attributable to both CL and $V_{\mathrm{d}}$. Differences in studies preclude final conclusions and warrant further investigation. Pediatric patients with $\mathrm{CF}$ might need a higher itraconazole dose as a considerably lower exposure is reported compared with patients without CF.

Population pharmacokinetic studies included allometrically scaled bodyweight on itraconazole pharmacokinetic parameters. As itraconazole and hydroxy-itraconazole are highly bound to plasma protein, the unbound drug concentrations of itraconazole and hydroxy-itraconazole could be interesting variables for future research specifically in the critically ill population. Research in critically ill populations might be of interest in resource-poor countries where posaconazole and voriconazole may not be available.

Itraconazole is not approved for patients aged $<18$ years in the labels, but international guidelines provide a dose recommendation for patients aged $\geq 2$ years for both prophylaxis and treatment. Agreement between labels and guidelines is important for clinical practice and needs to be established.

\section{Voriconazole}

Voriconazole was both European Medicines Agency and FDA approved in 2002 for adult patients and has been available as oral tablets, oral suspension, and powder for concentrate for solution $[5,46]$. The current approved indications for both adult and pediatric patients aged $\geq 2$ years are treatment of invasive aspergillosis, candidemia in patients without neutropenia, esophageal candidiasis, infections caused by Scedosporium and Fusarium species [5, 46], fluconazole-resistant invasive Candida infections, and prophylaxis of IFD in high-risk allogenic HSCT [46]. The labels, the pediatric ESCMID-ECMM guideline for invasive aspergillosis, and the pediatric ESCMID invasive candidiasis guideline provide dose recommendations for pediatric patients aged $\geq 2$ years. For prophylaxis and treatment of both invasive aspergillosis and candidiasis, a loading dose of $9 \mathrm{mg} / \mathrm{kg}$ twice daily on day 1 , followed by $8 \mathrm{mg} / \mathrm{kg}$ twice daily intravenously or $9 \mathrm{mg} / \mathrm{kg}$ (maximum $350 \mathrm{mg}$ ) twice daily for the oral formulations in pediatric patients aged 2-11 years or aged $12-14$ years $(<50 \mathrm{~kg})$ is recommended. A loading dose of $6 \mathrm{mg} / \mathrm{kg}$ twice daily on day 1 , followed by $4 \mathrm{mg} /$ $\mathrm{kg}$ twice daily intravenously or $200 \mathrm{mg}$ twice daily for the oral formulations is recommended in pediatric patients aged $12-14$ years $(\geq 50 \mathrm{~kg})$ or aged $\geq 14-15$ years $[1,2,5,46]$.

In adults, voriconazole is characterized by a $F$ of $96 \%$ for both tablets and suspension [5], which makes it possible to switch between the two available formulations. As food intake can reduce voriconazole absorption, both oral formulations are advised to be administered in a fasted state [5, 47]. The $V_{\mathrm{d}}$ of voriconazole is around $4.6 \mathrm{~L} / \mathrm{kg}$. [5] The distribution of voriconazole is suggested to be extensive into different body tissues, including the cerebrospinal fluid [48] and aqueous and vitreous parts of the eye [49]. Voriconazole is bound to plasma proteins for around 58\% [5]. Voriconazole is characterized by nonlinear pharmacokinetics in adult patients. The main CYP450 enzyme involved in the metabolism of voriconazole is CYP2C19 with also CYP2C9 and CYP3A4 playing a less prominent role (Table 1). Elimination via renal excretion accounts for only $2 \%$ in its unchanged form $[5,46]$.

\subsection{Non-Compartmental Analysis of Voriconazole PK in Pediatric Patients}

There are no NCA of voriconazole PK available in neonates and infants. Five NCA are available in pediatric patients aged 2-17 years. A detailed overview of the dosing regimens and voriconazole pharmacokinetic results is given in Table 9. Patients with hematological and non-hematological malignancies and patients undergoing BMT or HSCT were included in these studies. Voriconazole was administered either orally or in a combined intravenous to oral regimen. The oral voriconazole dose was from 4 to $9 \mathrm{mg} / \mathrm{kg}$ (maximum $350 \mathrm{mg}$ ) twice daily or was fixed at 200 or $300 \mathrm{mg}$ twice daily. The intravenous voriconazole dose was from 4 to $8 \mathrm{mg} / \mathrm{kg}$ twice daily, either with or without a loading dose of 6 to $9 \mathrm{mg} / \mathrm{kg}$ twice daily [50-54]. 
Overall, only one study reported the $F$ of voriconazole from 43.6 to $90.0 \%$ [52]. This $F$ in pediatric patients was lower compared with the $F$ of $96 \%$ seen in adults [5]. In the other studies, a lower $F$ was hypothesized, as lower exposures were reported after oral administration compared with exposures after intravenous administration [50, $51,54]$. Unlike observations in adults where food intake reduces voriconazole absorption $[5,46]$, it remains unclear if the influence of food intake attributes to the variable $F$ of voriconazole in pediatric patients. The reported lower $F$ and subsequent lower exposure after oral administration imply that there is no bioequivalence between intravenous and oral formulations of voriconazole in pediatric patients. Two studies stratified pharmacokinetic results of voriconazole by age $[52,54]$. One of these studies reported an overall comparable exposure of voriconazole in the group aged $2-5$ years and aged 6-11 years after administration of 4,6 , or $8 \mathrm{mg} / \mathrm{kg}$ of voriconazole in a twice-daily intravenous to oral regimen. This study also reported a $\sim 2.5$ times increased exposure after increasing voriconazole from 4 to $8 \mathrm{mg} / \mathrm{kg}$, suggesting non-linear PK in these pediatric patients over a dose range of $4-8 \mathrm{mg} / \mathrm{kg}$ [52]. The other study administered voriconazole according to the current labels and guidelines. For a detailed description of the dosing strategies, see Table 9. This study reported that patients aged $12-14$ years $(<50 \mathrm{~kg})$ had a higher exposure compared with patients aged 2-11 years and that patients aged $12-14$ years $(\geq 50 \mathrm{~kg})$ had a lower exposure compared with patients aged $<15$ years $(<50 \mathrm{~kg})$ [54]. The sample sizes in the different age groups were small and the authors mentioned that the CYP2C19 genotype in their Asian population might also have played a role in the differences in voriconazole PK [54]. Two studies showed an overall higher exposure of voriconazole compared with the other studies $[53,54]$. This higher exposure might be explained by the higher dosing regimens used.

\subsection{Population Pharmacokinetic Analysis of Voriconazole in Pediatric Patients}

There are no population pharmacokinetic analyses of voriconazole available in neonates. One study included infants, but did not describe the pharmacokinetic results for this population separately [55]. In total, nine studies were performed in pediatric patients aged $0.8-21$ years [55-63], of which two studies pooled data of three earlier published studies $[57,62]$ and included data of healthy adult patients [57]. A detailed overview of the dosing regimens and voriconazole pharmacokinetic results is given in Table 10. These studies included immunocompromised patients with hematological or non-hematological diseases, immunodeficiency or autoimmune diseases, liver transplantation, $\mathrm{CF}$, other infections/ diseases or undergoing HSCT or BMT [55-63]. Voriconazole was administered either intravenously [55, 61, 63], orally [55], or in a combined intravenous to oral regimen [56-60, 62]. All studies reported PK of voriconazole in a two-compartment model [55-62] and one study included also one compartment for the metabolite of voriconazole [63]. The models included delayed absorption [55, 57, 59] and first-order absorption [55-60, 62] and either linear [61], nonlinear $[55,56,58,60,62]$, or mixed linear and nonlinear elimination $[57,59]$. In one study, voriconazole elimination was included as linear CL but in addition also as non-linear CL to its metabolite [63]. Two other studies included both concentration- and time-dependent voriconazole elimination $[57,59]$. The PK models and covariates tested are summarized in Table 11.

Seven studies in pediatric patients administered either an oral solution or tablets of voriconazole in which the $F$ was from 44.6 to $85 \%$ [55-60, 62]. The $F$ found in these studies was also lower compared with the $F$ of $96 \%$ reported in adults [5]. Similar to findings in the NCA, it remains unclear if the influence of food was attributed to this difference. The $K_{\mathrm{a}}$ had a range of $0.43-1.53 \mathrm{~h}^{-1}[55-60,62]$. Allometrically scaled bodyweight with fixed exponents [56-60, 63] was added on either CL [57, 59, 63], $V_{\mathrm{d}}$ [57-60, 63], and/or maximum rate of enzyme activity [56-60, 63]. Two studies included patients aged $<2$ years [55, 63], of which one study had sufficient information to include a maturation factor to the pharmacokinetic model [63]. Two other studies incorporated the CYP2C19 genotype [61, 62], alanine aminotransferase (ALT) [61, 62], and alkaline phosphatase on CL. In these studies, the CYP2C19 genotype in the combined group of heterozygous extensive/poor CYP2C19 metabolizers [61, 62], ALT [61, 62], and alkaline phosphatase [61] significantly decreased CL, but according to the authors these variables were not predictive for voriconazole CL [61, 62]. Other covariates included linearly scaled weight and age on CL and $V_{\mathrm{d}}[55]$.

\subsection{Physiologically Based PK of Voriconazole}

One physiologically based pharmacokinetic model was developed for voriconazole in children. The physiologically based pharmacokinetic-derived values from the initial oral model showed an overprediction for $F$, area under the curve (AUC), and maximum serum concentration in children, which decreased substantially after adding intestinal CL to the model. Intestinal first-pass metabolism might explain the lower bioavailability of voriconazole in children compared with adults [64].

\subsection{Summary of Findings and Recommendations}

The PK of voriconazole in neonates and infants and children aged $<2$ years is lacking, and future studies should take these patient populations into account. Future research 


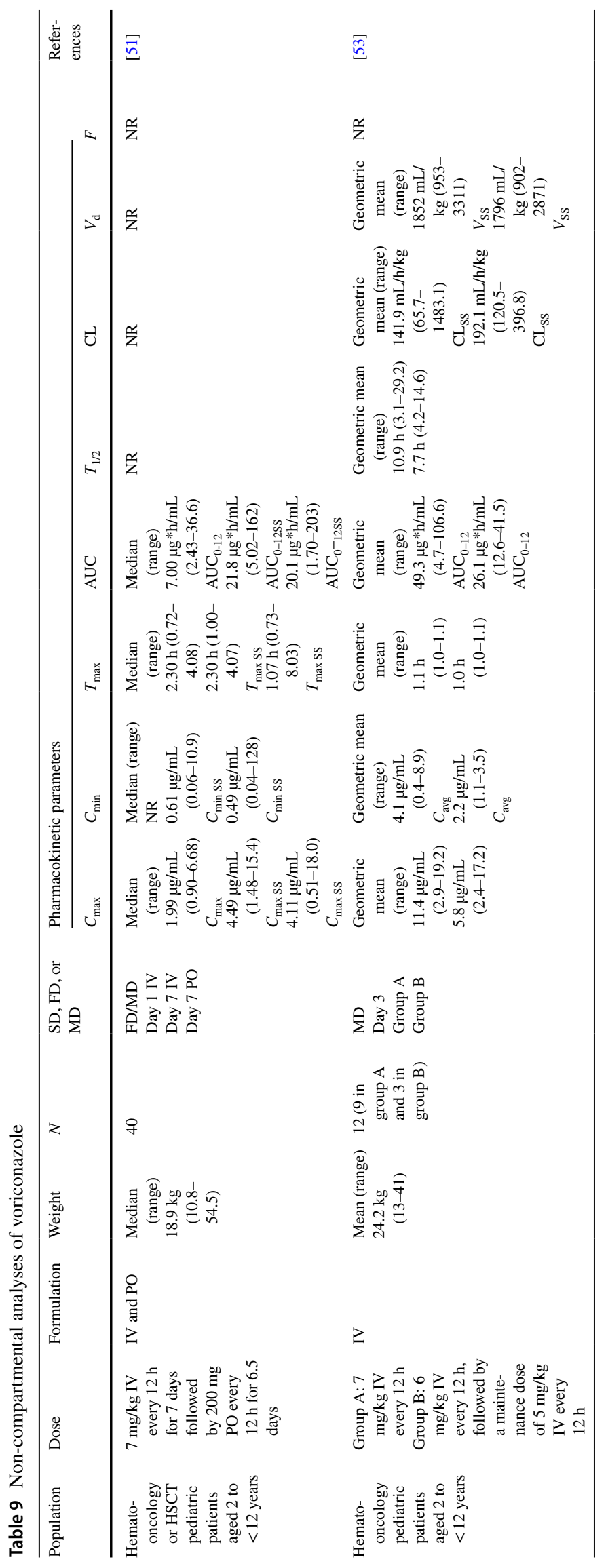




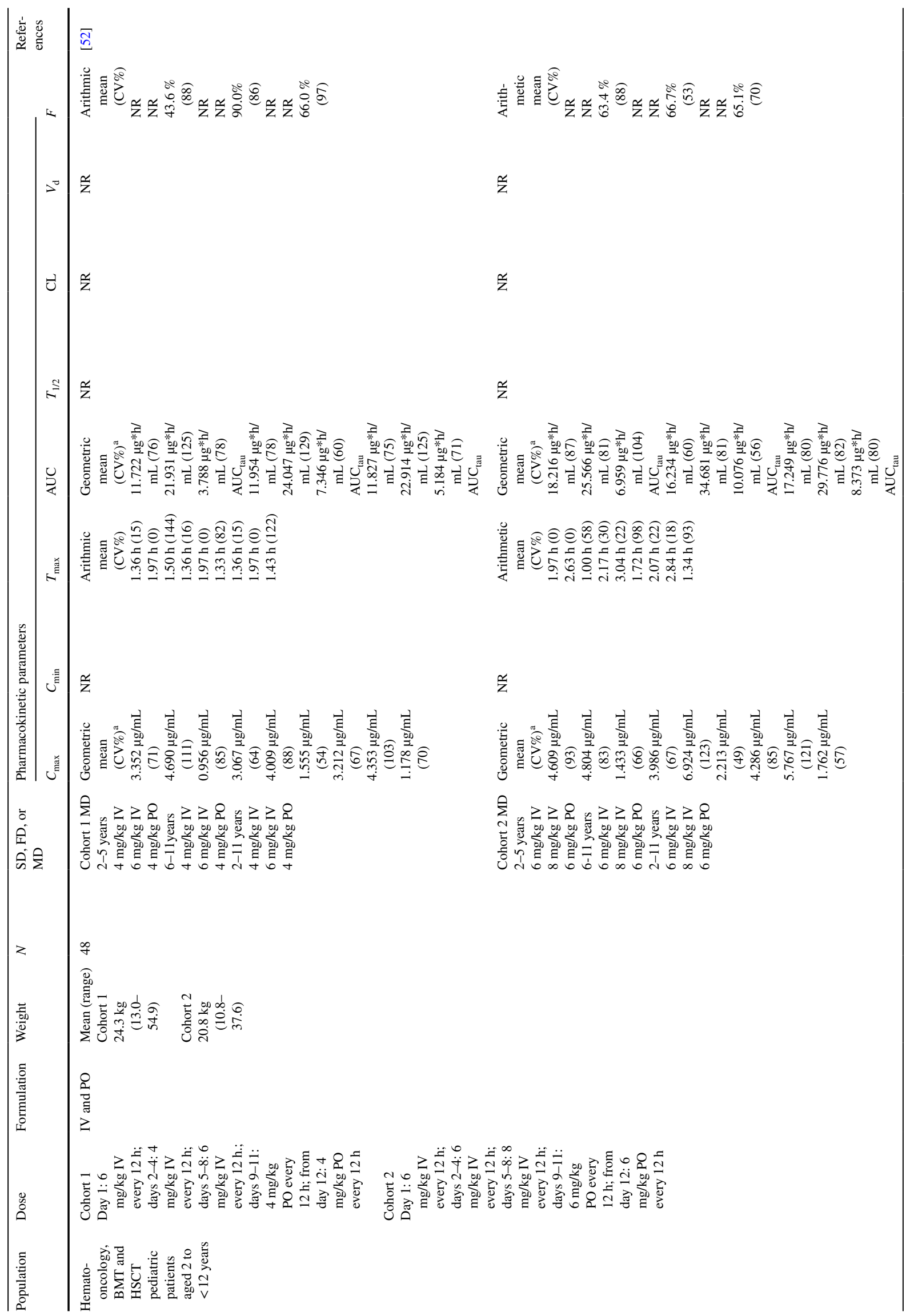




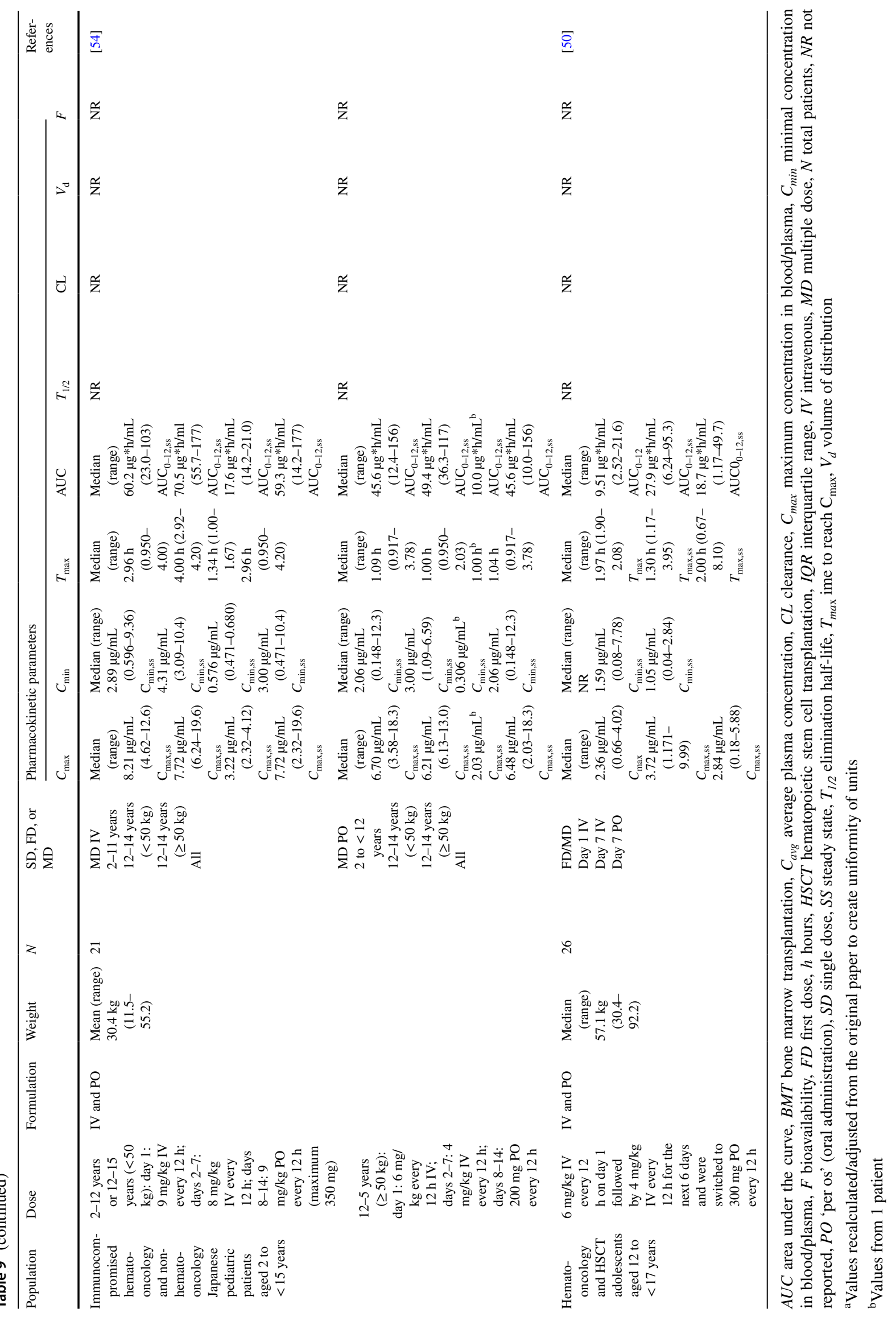




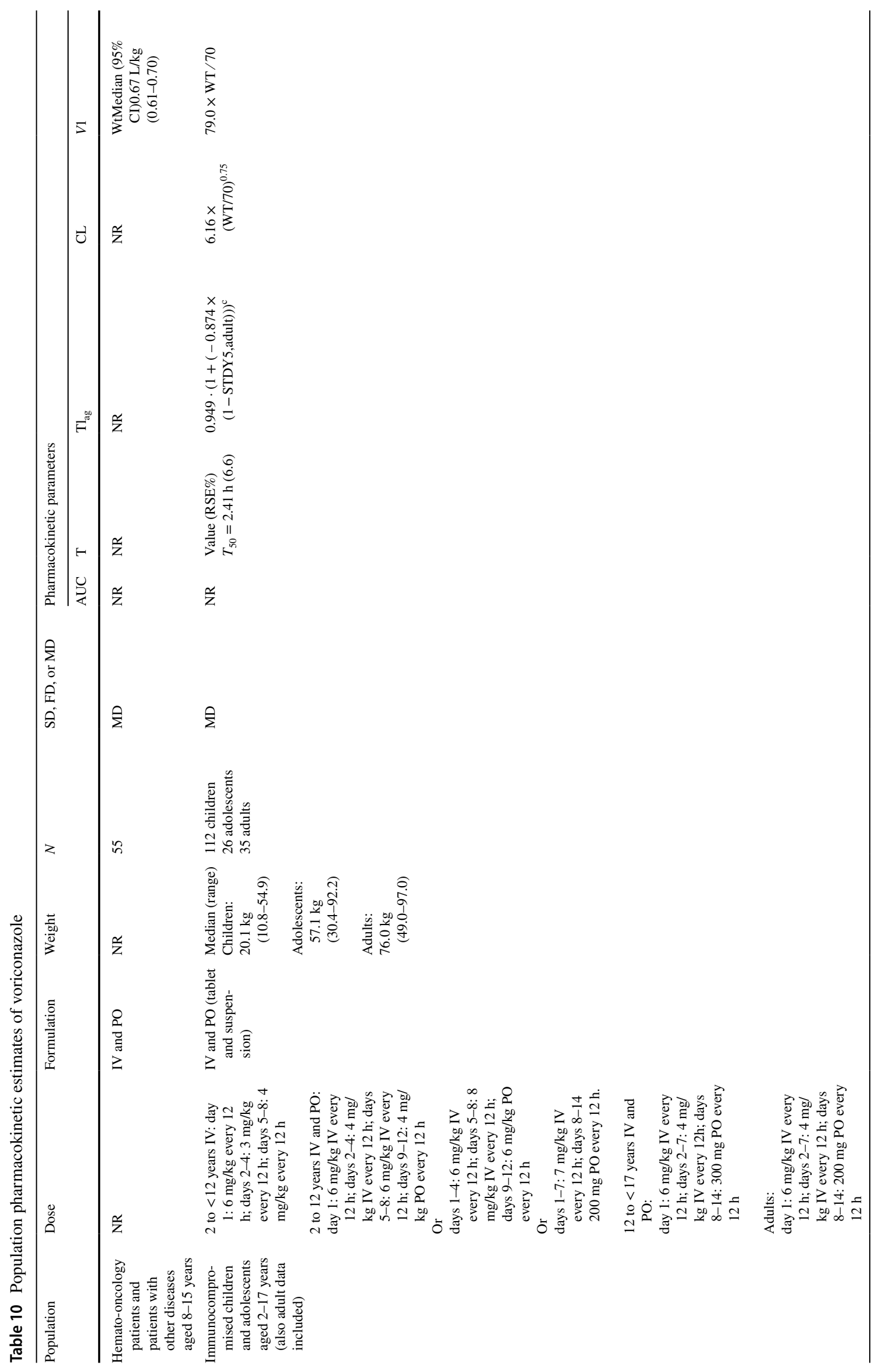




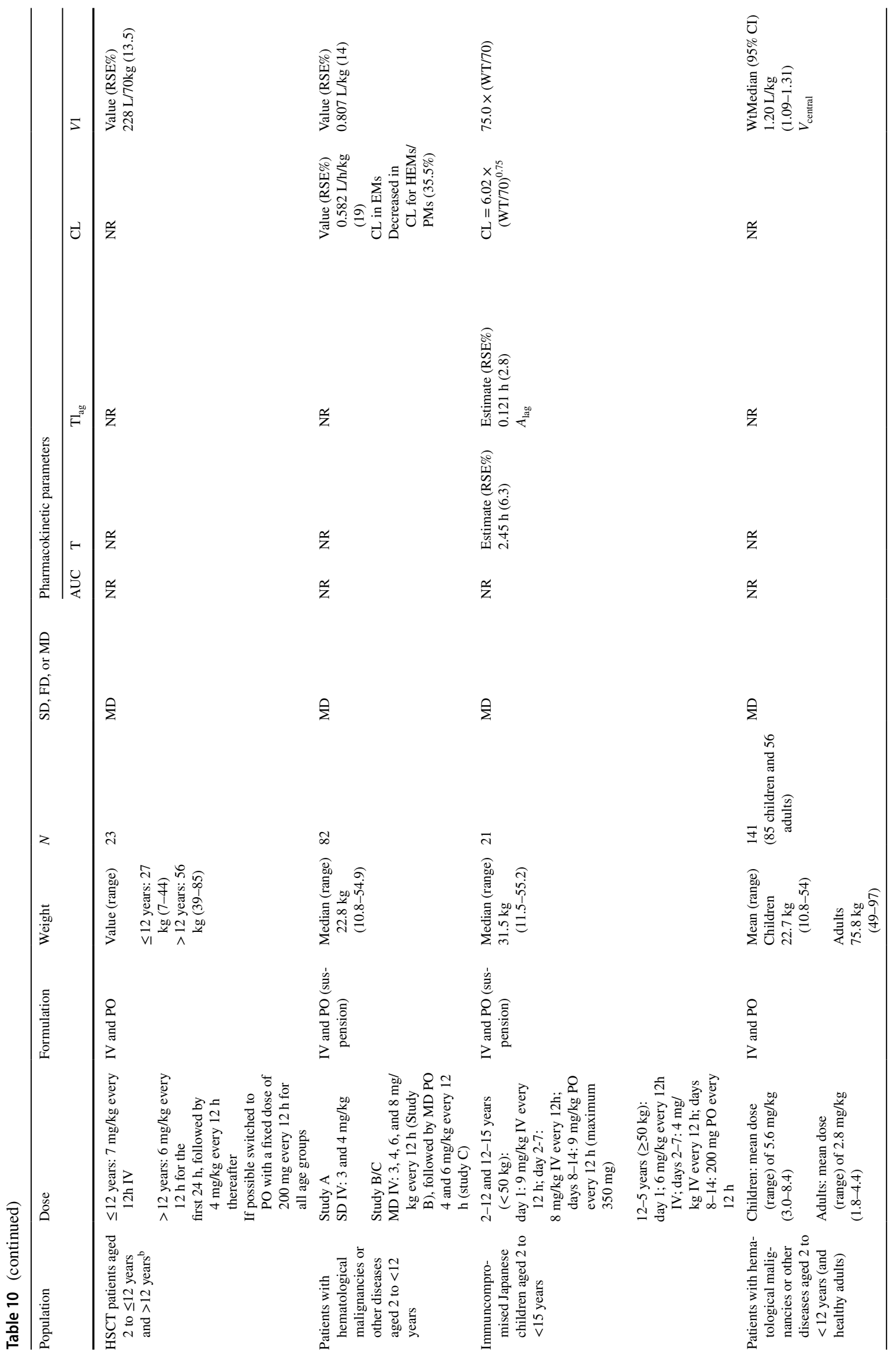




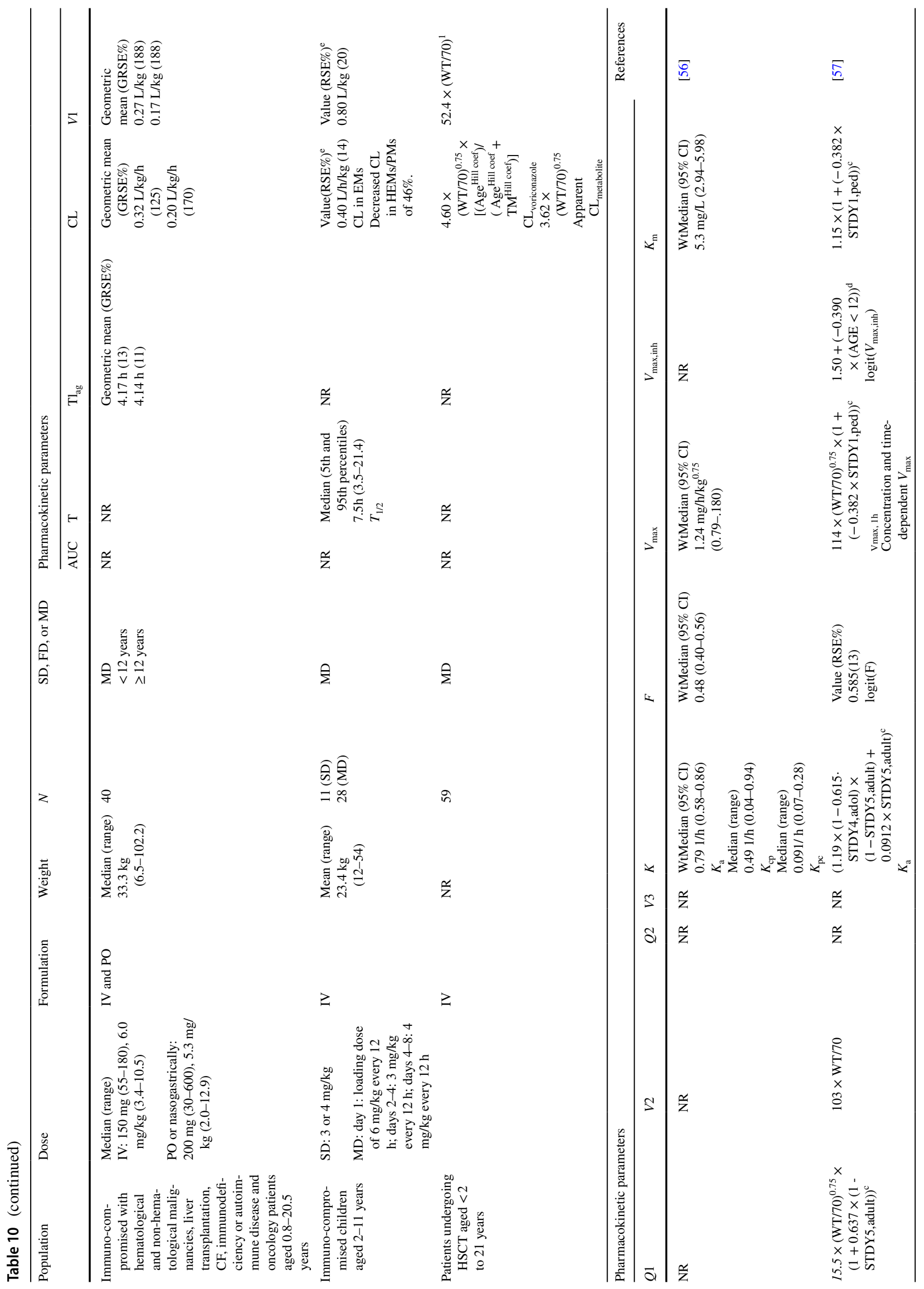




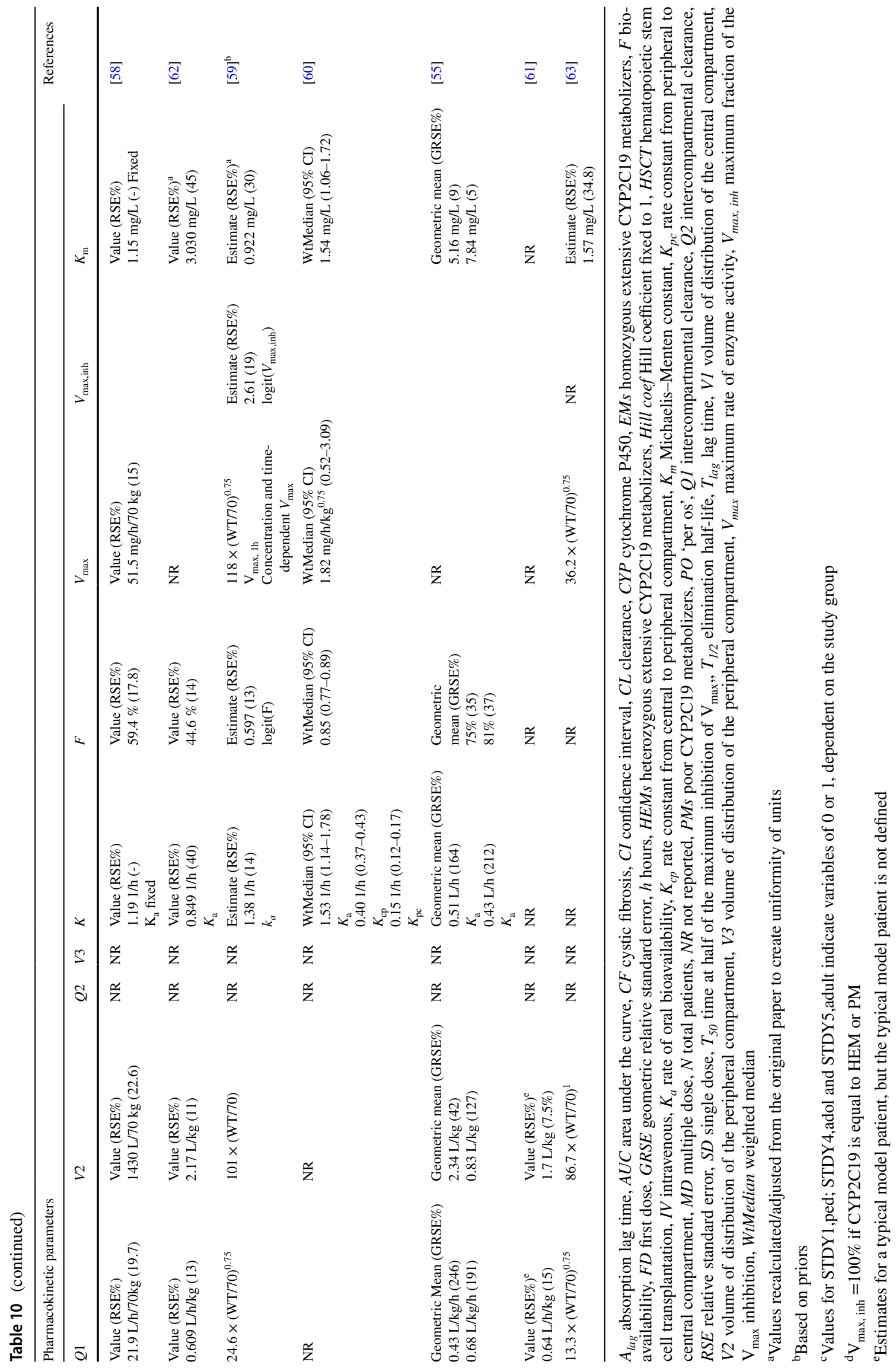


should further focus on the highly variable $F$, differences in $F$ between the oral formulations, the linear or non-linear relationship of voriconazole elimination, and PK in critically ill pediatric patients.

None of the reports highlight the difference in $F$ of the oral solution and tablets. In contrast to adults, it seems that there is no bioequivalency between oral and intravenous formulations in pediatric patients. It is unclear if the intake of food or gastric-emptying time is (partly) responsible for this variability and/or if the influence of intestinal first-pass metabolism might play a role. These questions need to be further explored. Switching from intravenous voriconazole to oral formulations cannot be done as straightforwardly as in adults but should be accompanied by therapeutic drug monitoring.

Noncompartmental analyses report that patients aged $<12$ years seem to have a higher CL and $V_{\mathrm{d}}$ compared with patients aged $\geq 12$ years and therefore the recommended loading dose and maintenance doses of voriconazole is higher in patients aged 2-11 years compared with those above 12 years. Some population pharmacokinetic studies reported that the CYP2C19 genotype and ALT values were significant covariates on voriconazole CL, but were not predictive for voriconazole CL. Although CYPC19 might be correlated with voriconazole CL, upfront dose adjustments in clinical practice are not yet advised in populations with a low prevalence of homozygous allele variations. Further research is needed to explain the differences of voriconazole PK in pediatric patients, to explore the influence of CYP2C19, and to reflect on the role of ALT as a surrogate marker for liver function. Additionally, other possible elimination routes (i.e., flavin-containing monooxygenase 3 [65]) might be interesting topics to explore.

\section{Posaconazole}

In 2005, posaconazole received European Medicines Agency marketing authorization and in 2006 FDA approval for adult patients $[8,66]$. The currently available formulations include a concentrate for solution for infusion, an oral suspension, and gastro-resistant tablets [66]. The FDA approved posaconazole in pediatric patients aged $>13$ years for prophylaxis and treatment of invasive aspergillosis and invasive candidiasis [8], but in Europe posaconazole is not approved in pediatric patients aged $<18$ years [66]. Both the new solid oral tablet and the intravenous solution of posaconazole require a loading dose of double the maintenance dose, whereas this loading dose is not of value for the marketed oral suspension. In the pediatric ESCMID-ECMM guideline for invasive aspergillosis, the recommended dose for posaconazole prophylaxis for patients aged $\geq 13$ years is $300 \mathrm{mg}$ once daily of the gastro-resistant tablet or a dose of
$200 \mathrm{mg}$ three times daily of the marketed oral suspension. For salvage therapy of a proven/probable invasive aspergillosis for patients aged $\geq 13$ years, $300 \mathrm{mg}$ once daily of the gastro-resistant tablet or intravenous formulation or a dose of either $400 \mathrm{mg}$ twice daily or $200 \mathrm{mg}$ four times daily of the marketed oral suspension is recommended [1]. The posaconazole dosing in the setting of prophylaxis for invasive candidiasis is identical to the dosing regimen of the marketed oral suspension for prophylaxis of invasive aspergillosis [2]. All the above-mentioned guidelines recommend using the gastro-resistant tablet over the marketed oral solution because of the anticipated more favorable oral bioavailability of the gastro-resistant tablet.

The $F$ of posaconazole is only reported for adult patients receiving the gastro-resistant tablets and is around 54\% [8]. As the $F$ of the marketed oral suspension is not available in the public domain, bioequivalence between the formulations cannot be assured. Both the marketed oral suspension and gastro-resistant tablets show saturable absorption, but for the gastro-resistant tablets this was only seen for daily doses above $800 \mathrm{mg}$ of posaconazole [67, 68]. Absorption of the marketed posaconazole suspension is significantly influenced by food intake and administration in a fed state is advised [69]. The gastro-resistant tablets are less prone to food effects [66], but a fed state can still increase the absorption by $\sim 1.5$ times [70]. The tablet cannot be broken because of the gastro-resistant coating, which makes it difficult to administer these tablets to patients who are unable to swallow. The mean apparent $V_{\mathrm{d}}\left(V_{\mathrm{d}} / F\right)$ of posaconazole is $287 \mathrm{~L}$ for the gastro-resistant tablet and the $V_{\mathrm{d}} / F$ is around $1774 \mathrm{~L}$ for the marketed oral suspension [8]. Posaconazole penetrates into a variety of tissues, including the lung, heart, kidney, and liver, but penetrates poorly into brain tissue [71] and cerebrospinal fluid [72]. Posaconazole is bound to plasma proteins for $>98 \%$ [8]. In contrast to the other azoles, posaconazole is metabolized via uridine diphosphate glucuronosyltransferase enzymes, and particularly uridine diphosphate glucuronosyltransferase 1A4 (Table 1) [73]. About $77 \%$ of radioactive-labeled posaconazole was retrieved in the feces of which $66 \%$ was the parent compound. The formed metabolites that were excreted in the urine and feces accounted for about $17 \%$ of the radioactivelabeled posaconazole $[8,66]$. Mean $\mathrm{CL}$ is $7.3 \mathrm{~L} / \mathrm{h}[8]$.

\subsection{Non-Compartmental Analysis of Posaconazole PK in Pediatric Patients}

Currently, there are no NCA studies of posaconazole PK performed in neonates. A detailed overview of the dosing regimens and posaconazole PK results is given in Table 12. Three NCA were performed in immunocompromised patients aged 3 months to $<18$ years. [74-76] Patients with hematological and non-hematological malignancies or 


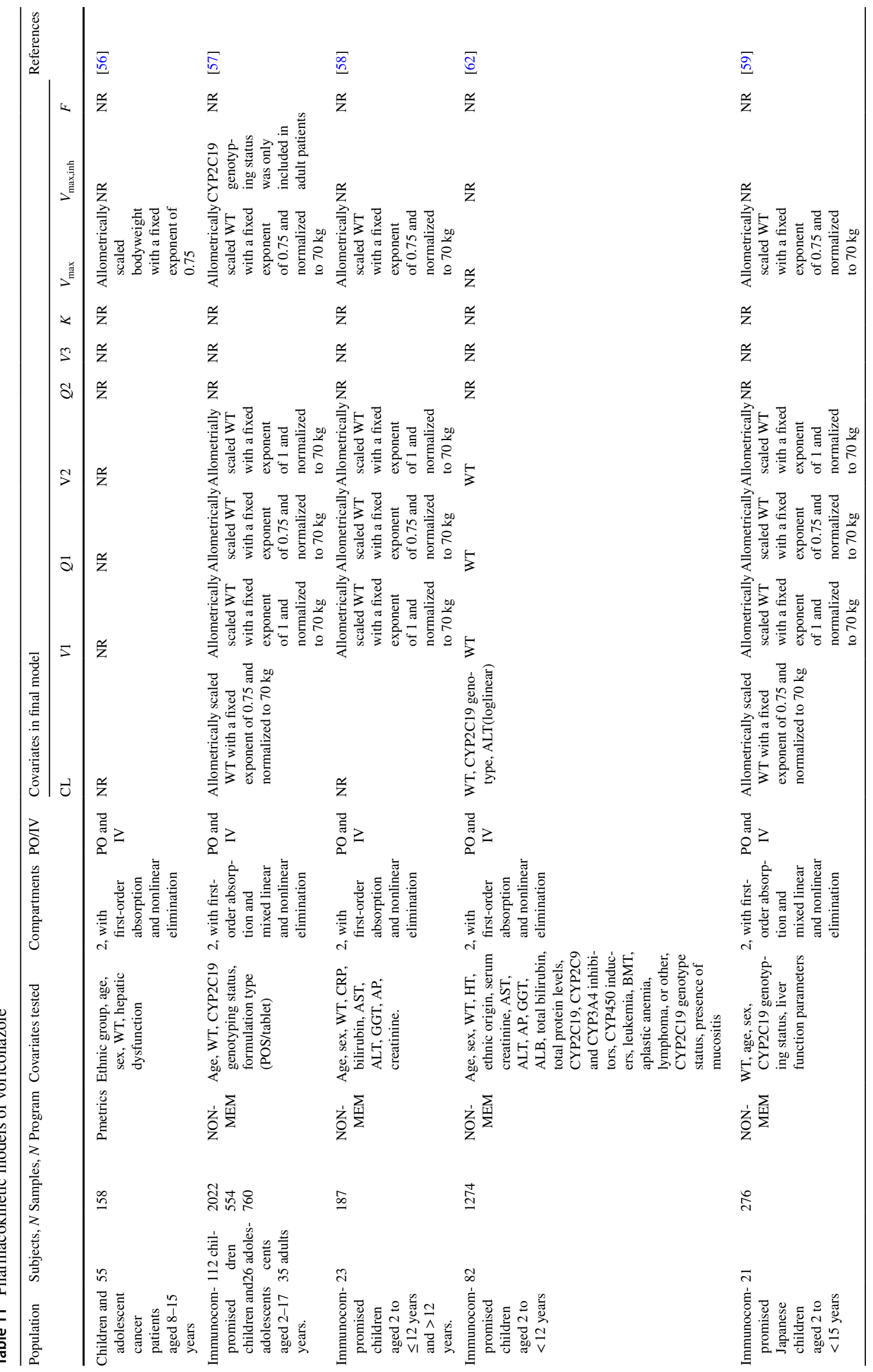




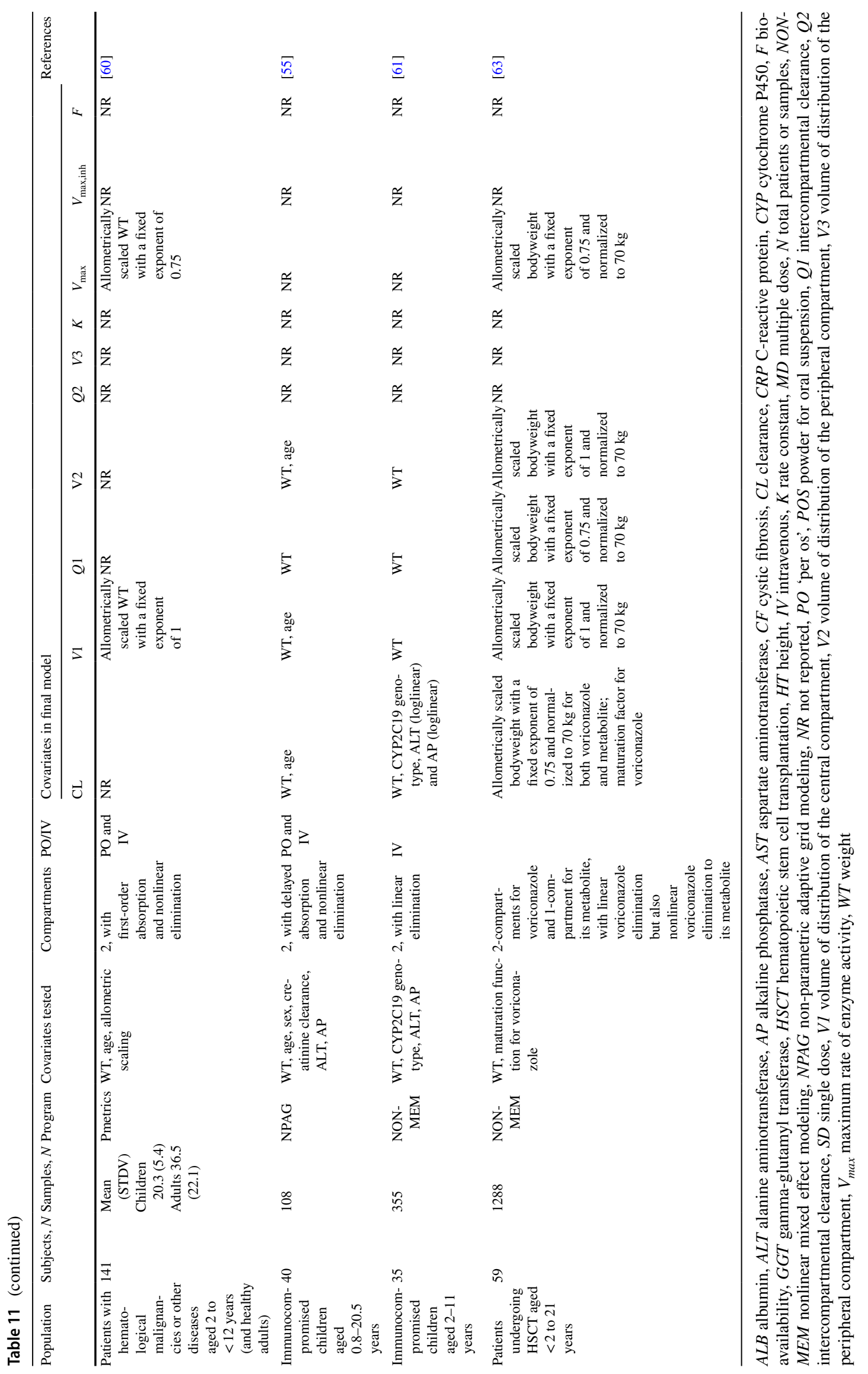


undergoing HSCT were included in these studies. In two studies, posaconazole was only administered as the marketed oral suspension. The relative $F$ of posaconazole was not determined in these studies [74, 75]. In the other study, posaconazole was administered as a not yet marketed new formulation, a powder for oral suspension (PFS), as well as an intravenous solution [76]. The first NCA investigated posaconazole orally as the marketed suspension at 6 or $9 \mathrm{mg} /$ $\mathrm{kg}$ in a two or three times-daily regimen in three different age groups [74]. The second study used the marketed oral posaconazole suspension as $120 \mathrm{mg} / \mathrm{m}^{2}$ based on body surface area (BSA) [75]. In the third study, posaconazole was investigated as either an intravenous solution or as the new oral PFS at $3.5 \mathrm{mg} / \mathrm{kg}, 4.5 \mathrm{mg} / \mathrm{kg}$, or $6 \mathrm{mg} / \mathrm{kg}$ in a twicedaily regimen on day 1 , followed by the same dose in a oncedaily regimen in two different age groups [76].

Increasing the daily dose from 6 to $9 \mathrm{mg} / \mathrm{kg}$ or increasing the dosing frequency of the marketed suspension from two times daily to three times daily did not increase the exposure of posaconazole. This suggests saturable absorption in pediatric patients, which is also seen in adults. The authors suggested that children aged $>7$ years showed higher exposures compared with patients aged 2-7 years [74], implying that higher dosages are needed in younger patients to achieve a comparable exposure to older patients. A dosing regimen based on BSA resulted in a comparable mean exposure as children aged 7-17 years on a 6-mg/kg twice-daily regimen [75]. However, data based on BSA were not available for different age groups and exposure in the youngest patients is therefore not exactly known with this approach. Administering posaconazole intravenously or as a PFS in a once-daily regimen (with a loading dose on day 1) resulted in higher exposures compared with the exposures after a twice-daily regimen of the marketed oral suspension in the previously described report $[74,76]$. Similarly to this earlier report, posaconazole exposure was lower in younger patients compared with older patients in all dosing groups [74, 76]. Furthermore, the exposure after oral PFS administration was lower compared with intravenously administered posaconazole. As suggested by the authors, there seems to be no bioequivalence between the intravenous and new PFS formulations in pediatric patients [76].

\subsection{Population Pharmacokinetic Analysis of Posaconazole in Pediatric Patients}

Currently, there are no population pharmacokinetic studies of posaconazole performed in neonates. One population pharmacokinetic model was published in 117 immunocompromised infants, children, and adolescents aged 0.5-18 years. A detailed overview of the dosing regimens and posaconazole pharmacokinetic results is shown in Table 13. Posaconazole was administered as the marketed suspension in the vast majority of these patients, with a mean daily dose of $13.11 \mathrm{mg} / \mathrm{kg}$ [77]. A one-compartment model fitted the data best. An overview of the pharmacokinetic model and covariates tested is given in Table 10. Allometrically scaled bodyweight was added on CL and $V_{\mathrm{d}}$ and covariates such as diarrhea and concomitant use of proton pump inhibitors decreased posaconazole bioavailability only after administration of the marketed suspension [77]. The pharmacokinetic models and covariates tested are summarized in Table 14

The relative $K_{\mathrm{a}}$ of the marketed suspension and tablets was $0.197 \mathrm{~h}^{-1}$ and $0.588 \mathrm{~h}^{-1}$, respectively. The relative $F$ of the marketed suspension and tablets was not described. A decrease of $33 \%$ in the relative $F$ of the marketed suspension was seen in patients with diarrhea and a $42 \%$ decrease in patients using proton pump inhibitors. As only the oral marketed formulations were used, $V_{\mathrm{d}} / F$ and apparent CL were determined. Allometrically scaled bodyweight normalized to $70 \mathrm{~kg}$ was added as covariate on posaconazole $V_{\mathrm{d}} / F$ and apparent CL [77].

\subsection{Summary of Findings and Recommendations}

Pediatric pharmacokinetic data of posaconazole are very limited, and future research is particularly needed to explain the PK of posaconazole in infants, and to further resolve its PK in children and adolescents. Research topics should include the $F$ of all the oral formulations and the PK in critically ill patients and patients with CF. Furthermore, the drug-drug interaction between posaconazole and CF transmembrane conductance regulator modulators might be an interesting research topic. In adults, the gastro-resistant tablets are the preferred formulation, but there are no pharmacokinetic data of this formulation available in pediatric patients. This oral tablet formulation urgently needs to be studied in children and adolescents to confirm that this is the most appropriate oral pharmaceutical formulation to be used. For patients who are unable to swallow tablets, the new PFS needs to be further explored. Other new child-friendly formulations allowing the administration of smaller dosages might be needed to further expand posaconazole treatment.

Although all studies administered posaconazole as an oral formulation, the absolute and/or relative $F$ were not described and need to be explored in pediatric patients. Exposures after administration of the not yet marketed posaconazole PFS were lower compared with intravenous administration, and suggests that there is no bioequivalence 
between these two formulations. Given the unknown $F$ of the marketed formulations and the non-bioequivalence between intravenous and PFS formulations, dosing of posaconazole and switching between formulations should be accompanied by therapeutic drug monitoring.

The majority of available pediatric NCA only administered the suspension of posaconazole as an oral formulation. These data confirm adult observations that the marketed suspension shows saturable absorption. The new posaconazole PFS that is not yet on the market shows higher exposures in a once-daily regimen compared with the twice-daily regimen of the current marketed posaconazole suspension. After administration of both oral and intravenous formulations, posaconazole exposure seems lower in younger patients and higher dosages might be needed to reach the same exposure as older patients.

The population PK study included allometrically scaled bodyweight on $C L$ and $V_{\mathrm{d}}$. Diarrhea and concomitant use of proton pump inhibitors were negatively associated with the relative $F$ of the marketed posaconazole solution. Because of the high protein binding of posaconazole, it might be interesting to explore the influence of its unbound drug concentrations on posaconazole PK.

\section{Isavuconazole}

The relatively new triazole isavuconazole is not licensed for pediatric patients. The European Medicines Agency approved isavuconazole for adult patients in 2014 and the FDA approved isavuconazole in 2016 [7, 78]. Available formulations include an oral formulation as hard capsules and an intravenous formulation as powder for concentrate for solution. In adult patients, isavuconazole is indicated for the treatment of invasive aspergillosis. In addition, it is licensed for mucormycosis for patients who have a contraindication or intolerance for amphotericin B [7, 78]. Isavuconazole has not yet been approved for pediatric patients and the international guideline does not provide recommendations for dosing of isavuconazole in pediatric patients [1]. Dose finding trials have been completed or are ongoing, thus more information is expected soon.

Isavuconazole is given as a pro-drug isavuconazonium sulfate. The oral $F$ of isavuconazonium sulfate is $98 \%$ in adults [7]. After a rapid and complete absorption, isavuconazonium sulfate is quickly and completely cleaved to isavuconazole [7]. Oral and intravenous formulations can be used interchangeably. Food intake or fluctuations in $\mathrm{pH}$ do not influence the absorption of isavuconazole [79]. Based mostly on animal research, isavuconazole widely distributes in different tissues, including the liver, lungs, eyes, kidneys, skin, bone, nasal mucosa, and brain [80]. Isavuconazole is bound to plasma proteins for $>99 \%$ and is metabolized by CYP3A4/A5 and uridine diphosphate glucuronosyltransferase (Table 1) [7].

To our current knowledge, there is only one pediatric study of isavuconazole available in the public domain outside of conference abstracts and case reports. This retrospective study included 29 patients with a hematological malignancy aged 3-18 years. In six patients, an 8-point sample curve was obtained over $12 \mathrm{~h}$. The demographics and dosing regimens are not reported for these six patients separately. The median $\mathrm{AUC}_{0-12 \mathrm{~h}}$ (range) in these six patients was $153.16 \mathrm{mg} \times \mathrm{h} / \mathrm{L}$ (86.31-169.45) [81]. Because of the small sample size and missing demographics and dosing information, it is difficult to draw any conclusions from these data.

\subsection{Summary of Findings and Recommendations}

Data on the PK of isavuconazole are urgently needed in pediatric patients including population pediatric PK data. Specifically for pediatric patients, information on $F$ including information on dosing via a nasogastric tube are needed as well as information on bioequivalence after the intake of whole or opened capsules. As isavuconazole is highly protein bound, more research is needed on unbound drug concentrations in, for instance, the critically ill patient populations.

\section{Conclusions}

This review shows that the PK of fluconazole is extensively studied in the neonatal population and the PK of voriconazole is extensively studied in children and adolescents. Isavuconazole, itraconazole, and posaconazole are studied to a limited extent. Fluconazole data in children and adolescents are understated, while for other triazoles pharmacokinetic data in neonates and infants urgently need to be studied. Future studies should explore the PK of the newest triazole agents, understanding the $F$ of the available formulations and learning more about interactions with food or administration over a nasogastric tube, the effect of CYP genotypes and other metabolic routes, the influence of other factors such as unbound drug concentrations for highly proteinbound agents, and the development and PK of new oral formulations that can easily be deployed in pediatric patients. In addition, information on the PK of triazoles in critically ill patient populations, the impact of dialysis, ECMO as well as renal or hepatic impairment is lacking in most cases and 


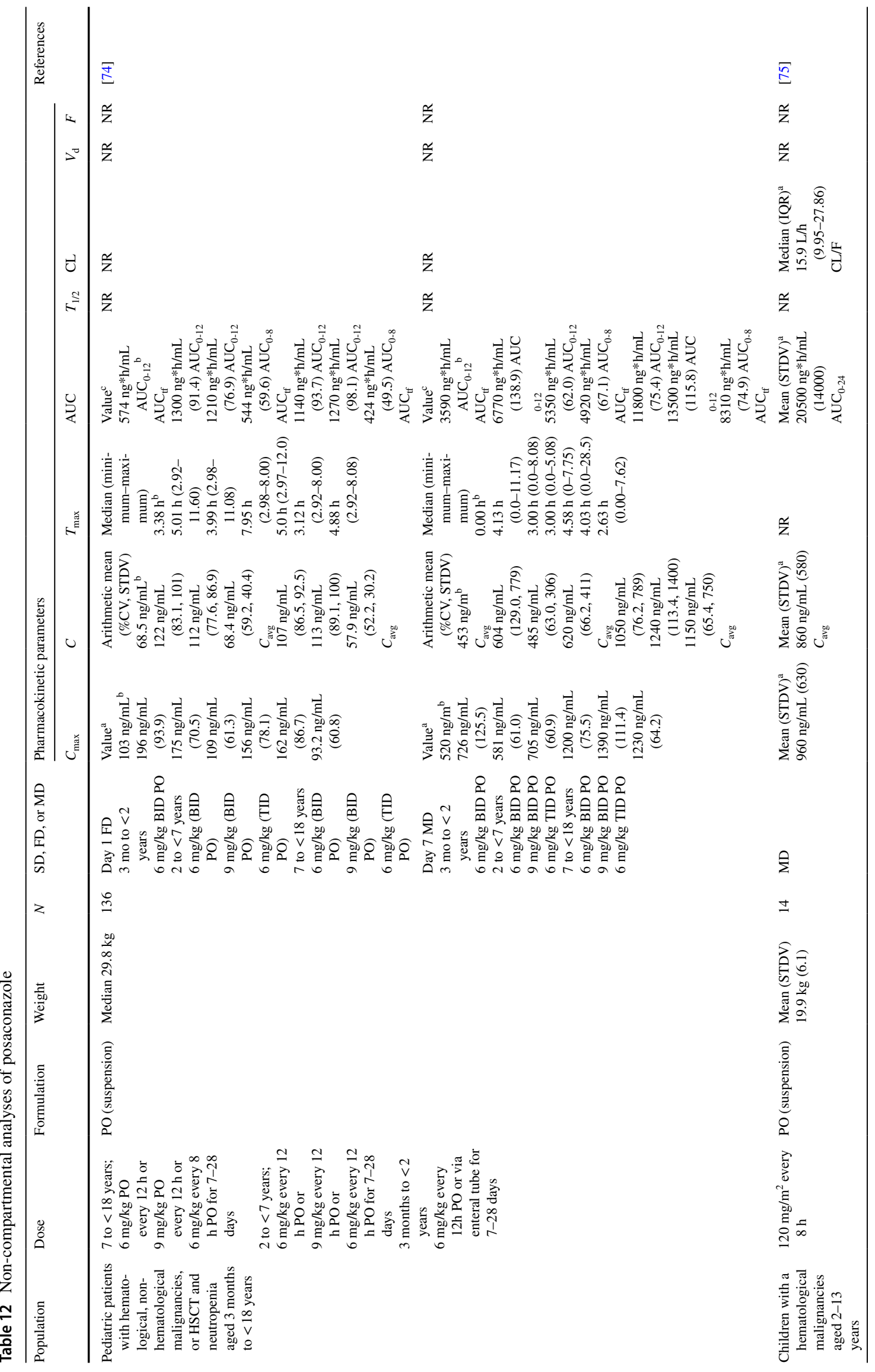




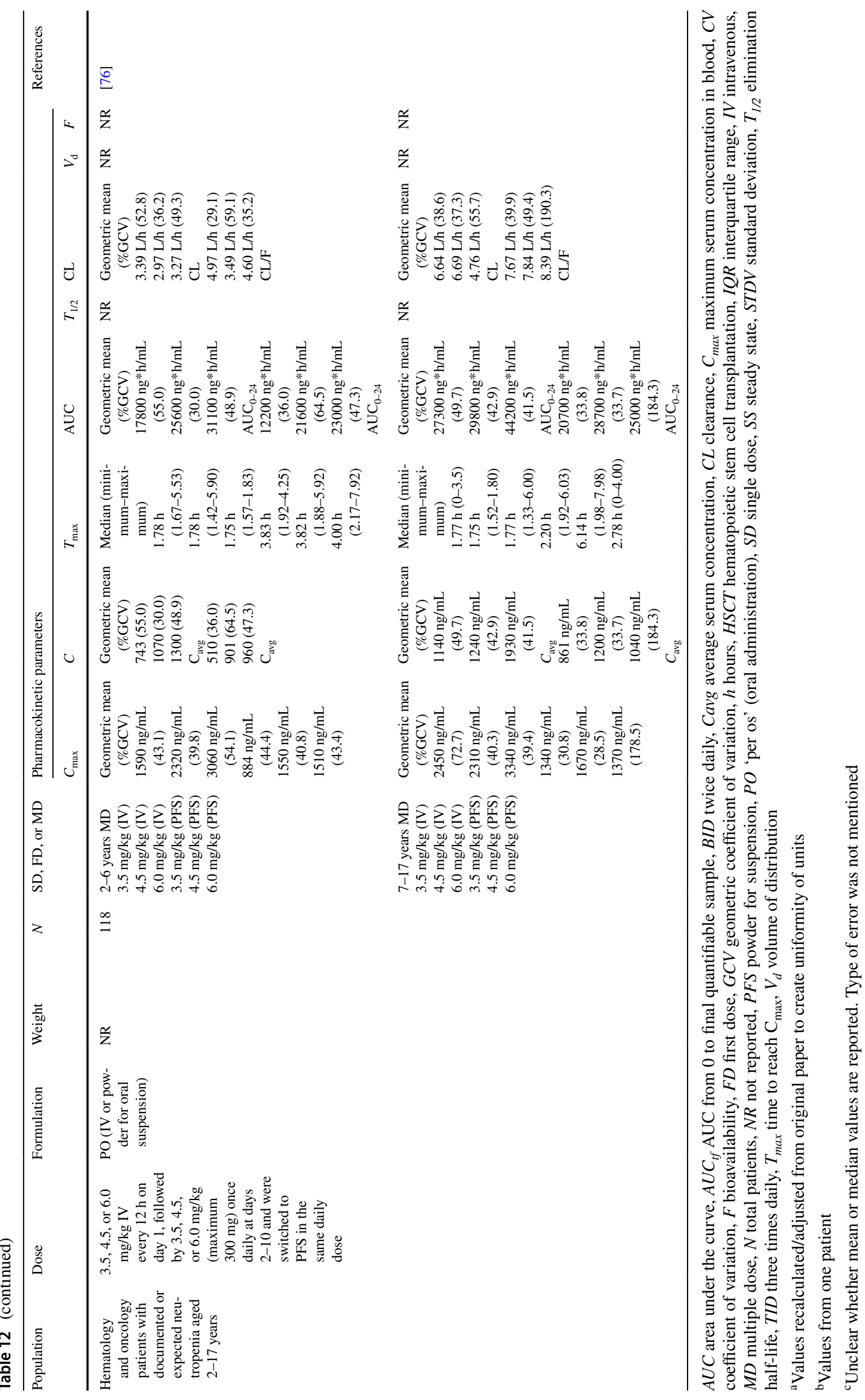




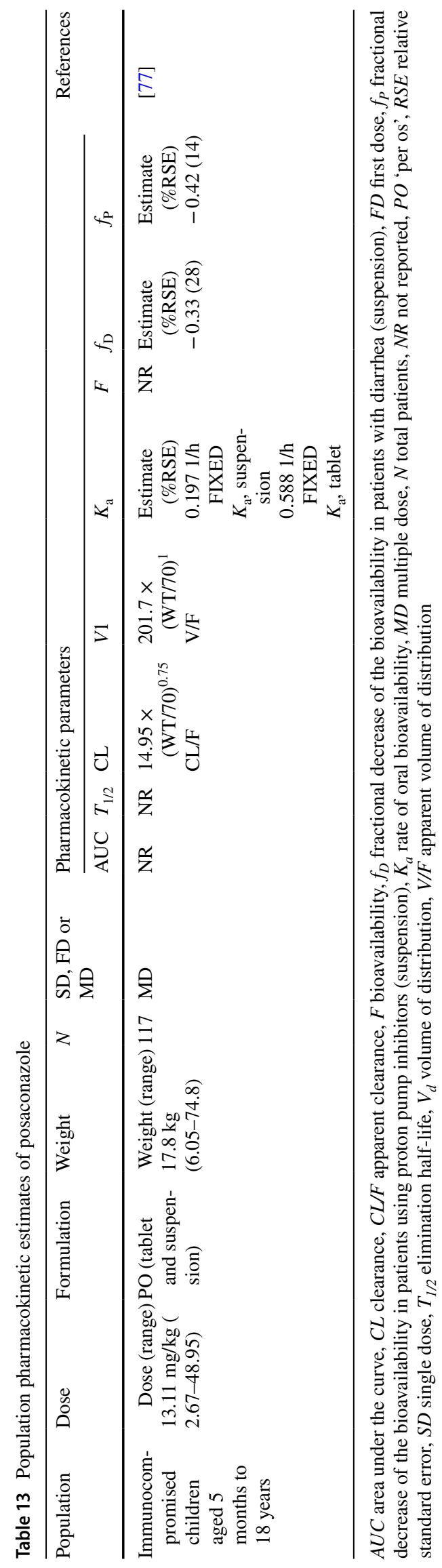




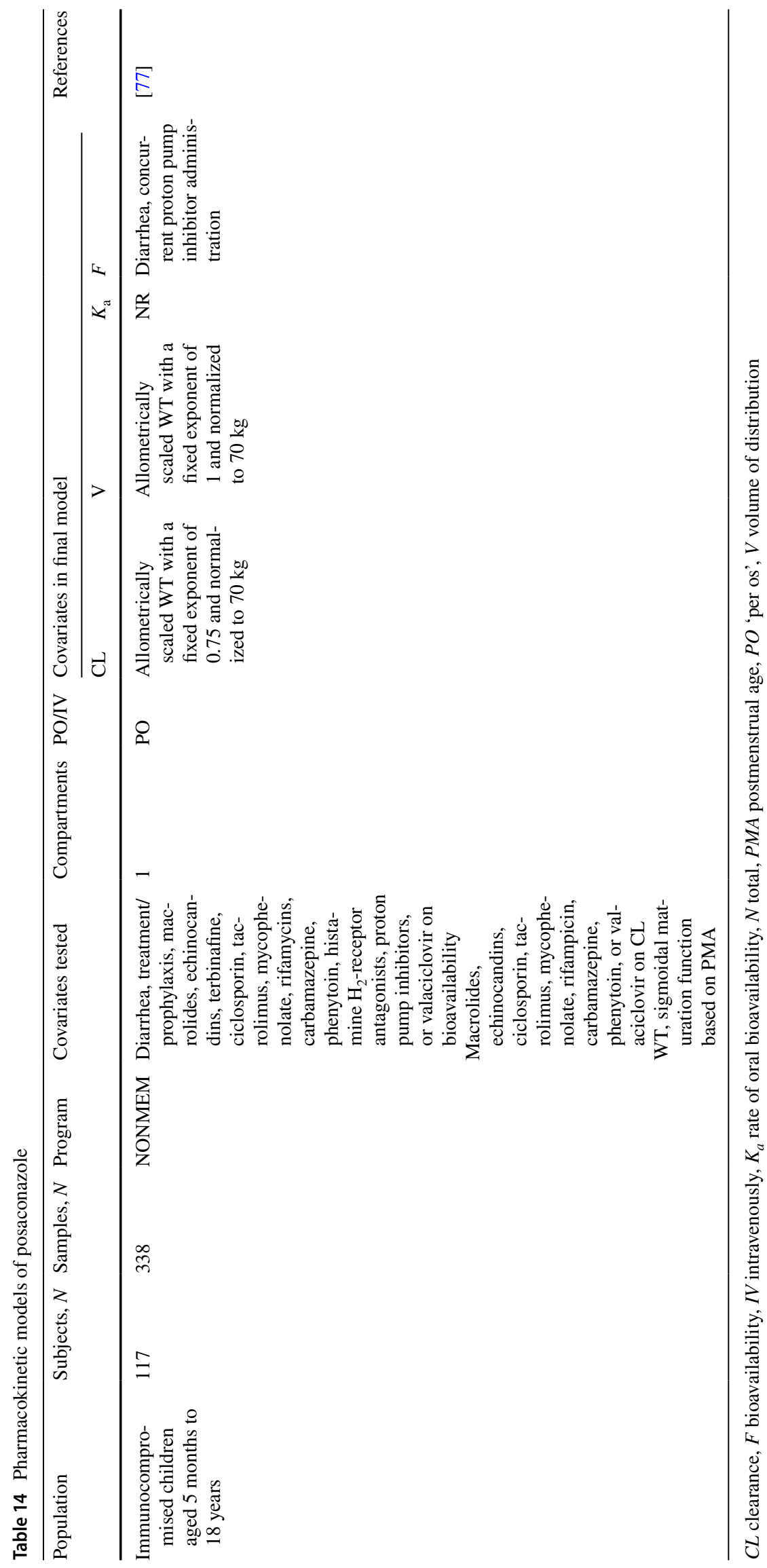


should warrant further exploration. Better understanding of the PK is necessary for optimal clinical care and remaining knowledge gaps will need to be clarified.

\section{Declarations}

Funding No sources of funding were received for the preparation of this article.

Conflict of interest Didi Bury, Wim J.E. Tissing, Eline W. Muilwijk, Tom F.W. Wolfs, and Roger J. Brüggemann have no conflicts of interest that are directly relevant to the content of this article. Disclosures outside of this work: Roger J. Brüggemann has served as a consultant to Astellas Pharma, Inc., F2G, Amplyx, Gilead Sciences, Merck Sharp \& Dohme Corp., and Pfizer, Inc., and has received unrestricted and research grants from Astellas Pharma, Inc., Gilead Sciences, Merck Sharp \& Dohme Corp., Mundipharma, and Pfizer, Inc. All contracts were through Radboudumc, and all payments were invoiced by Radboudumc.

Ethics approval Not applicable.

Consent to participate Not applicable.

Consent for publication Not applicable.

Availability of data and material Not applicable.

Code availability Not applicable.

Author contributions DB performed the literature search, selected articles, and drafted the manuscript together with RB. WT, TW, and EM provided a critical revision of the manuscript. All authors approved of the final version.

Open Access This article is licensed under a Creative Commons Attribution-NonCommercial 4.0 International License, which permits any non-commercial use, sharing, adaptation, distribution and reproduction in any medium or format, as long as you give appropriate credit to the original author(s) and the source, provide a link to the Creative Commons licence, and indicate if changes were made. The images or other third party material in this article are included in the article's Creative Commons licence, unless indicated otherwise in a credit line to the material. If material is not included in the article's Creative Commons licence and your intended use is not permitted by statutory regulation or exceeds the permitted use, you will need to obtain permission directly from the copyright holder. To view a copy of this licence, visit http://creativecommons.org/licenses/by-nc/4.0/.

\section{References}

1. Warris A, Lehrnbecher T, Roilides E, Castagnola E, Brüggemann RJM, Groll AH. ESCMID-ECMM guideline: diagnosis and management of invasive aspergillosis in neonates and children. Clin Microbiol Infect. 2019;25(9):1096-113. https://doi.org/10.1016/j. cmi.2019.05.019.

2. Hope WW, Castagnola E, Groll AH, Roilides E, Akova M, Arendrup MC, et al. ESCMID guideline for the diagnosis and management of Candida diseases 2012: prevention and management of invasive infections in neonates and children caused by Candida spp. Clin Microbiol Infect. 2012;18(Suppl. 7):38-52. https://doi. org/10.1111/1469-0691.12040.

3. Pappas PG, Kauffman CA, Andes DR, Clancy CJ, Marr KA, Ostrosky-Zeichner L, et al. Clinical practice guideline for the management of candidiasis: 2016 update by the Infectious Diseases Society of America. Clin Infect Dis. 2016;62(4):e1-50. https://doi.org/10.1093/cid/civ933.

4. FDA. FDA-approved drugs: Diflucan. https://www.accessdata.fda. gov/scripts/cder/daf/. Accessed 6 Apr 2020.

5. FDA. FDA-approved drugs: Vfend. https://www.accessdata.fda. gov/scripts/cder/daf/. Accessed 6 Apr 2020.

6. FDA. FDA-approved drugs: Sporanox. https://www.accessdata. fda.gov/scripts/cder/daf/. Accessed 6 Apr 2020.

7. FDA. FDA-approved drugs: Cresemba. https://www.accessdata. fda.gov/scripts/cder/daf/. Accessed 6 Apr 2020.

8. FDA. FDA-approved drugs: Noxafil. https://www.accessdata.fda. gov/scripts/cder/daf/. Accessed 6 Apr 2020.

9. EMA. Diflucan. https://www.ema.europa.eu/en/medicines/human/ referrals/diflucan\#all-documents-section. Accessed 6 Apr 2020.

10. CBG-MEB. Fluconazole. https://www.geneesmiddeleninform atiebank.nl. Accessed 25 Nov 2020.

11. Brammer KW, Farrow PR, Faulkner JK. Pharmacokinetics and tissue penetration of fluconazole in humans. Rev Infect Dis. 1990;12(Suppl. 3):S318-26. https://doi.org/10.1093/clinids/12. supplement_3.s318.

12. Saxen H, Hoppu K, Pohjavuori M. Pharmacokinetics of fluconazole in very low birth weight infants during the first two weeks of life. Clin Pharmacol Ther. 1993;54(3):269-77. https://doi.org/10. 1038/clpt.1993.147.

13. Nahata MC, Tallian KB, Force RW. Pharmacokinetics of fluconazole in young infants. Eur J Drug Metab Pharmacokinet. 1999;24(2):155-7. https://doi.org/10.1007/bf03190361.

14. Wong SF, Leung MP, Chan MY. Pharmacokinetics of fluconazole in children requiring peritoneal dialysis. Clin Ther. 1997;19(5):1039-47. https://doi.org/10.1016/s0149-2918(97) 80056-2.

15. Brammer KW, Coates PE. Pharmacokinetics of fluconazole in pediatric patients. Eur J Clin Microbiol Infect Dis. 1994;13(4):325-9. https://doi.org/10.1007/bf01974613.

16. Nahata MC, Brady MT. Pharmacokinetics of fluconazole after oral administration in children with human immunodeficiency virus infection. Eur J Clin Pharmacol. 1995;48(3-4):291-3. https://doi. org/10.1007/bf00198314.

17. Lee JW, Seibel NL, Amantea M, Whitcomb P, Pizzo PA, Walsh TJ. Safety and pharmacokinetics of fluconazole in children with neoplastic diseases. J Pediatr. 1992;120(6):987-93. https://doi. org/10.1016/s0022-3476(05)81975-4.

18. Friis-Hansen B. Body composition during growth. In vivo measurements and biochemical data correlated to differential anatomical growth. Pediatrics. 1971;47(1, Suppl. 2):264+.

19. Chen N, Aleksa K, Woodland C, Rieder M, Koren G. Ontogeny of drug elimination by the human kidney. Pediatr Nephrol. 2006;21(2):160-8. https://doi.org/10.1007/s00467-005-2105-4.

20. Kim YK, Lee J, Oh J, Rhee SJ, Shin SH, Yoon SH, et al. Population pharmacokinetic study of prophylactic fluconazole in preterm infants for prevention of invasive candidiasis. Antimicrob Agents Chemother. 2019;63(6):e01960-e2018. https://doi.org/10.1128/ aac.01960-18.

21. Momper JD, Capparelli EV, Wade KC, Kantak A, Dhanireddy R, Cummings JJ, et al. Population pharmacokinetics of fluconazole in premature infants with birth weights less than 750 grams. Antimicrob Agents Chemother. 2016;60(9):5539-45. https://doi.org/ 10.1128/aac.00963-16.

22. Leroux S, Jacqz-Aigrain E, Elie V, Legrand F, Barin-Le Guellec $\mathrm{C}$, Aurich B, et al. Pharmacokinetics and safety of fluconazole and micafungin in neonates with systemic candidiasis: a randomized, 
open-label clinical trial. Br J Clin Pharmacol. 2018;84(9):198999. https://doi.org/10.1111/bcp.13628.

23. Wade KC, Wu D, Kaufman DA, Ward RM, Benjamin DK Jr, Sullivan JE, et al. Population pharmacokinetics of fluconazole in young infants. Antimicrob Agents Chemother. 2008;52(11):40439. https://doi.org/10.1128/AAC.00569-08.

24. Piper L, Smith PB, Hornik CP, Cheifetz IM, Barrett JS, Moorthy $\mathrm{G}$, et al. Fluconazole loading dose pharmacokinetics and safety in infants. Pediatr Infect Dis J. 2011;30(5):375-8. https://doi.org/ 10.1097/INF.0b013e318202cbb3.

25. Watt KM, Benjamin DK Jr, Cheifetz IM, Moorthy G, Wade KC, Smith PB, et al. Pharmacokinetics and safety of fluconazole in young infants supported with extracorporeal membrane oxygenation. Pediatr Infect Dis J. 2012;31(10):1042-7. https://doi.org/10. 1097/INF.0b013e31825d3091.

26. Watt KM, Gonzalez D, Benjamin DK, Brouwer KLR, Wade KC, Capparelli E, et al. Fluconazole population pharmacokinetics and dosing for prevention and treatment of invasive candidiasis in children supported with extracorporeal membrane oxygenation. Antimicrob Agents Chemother. 2015;59(7):3935-43. https://doi. org/10.1128/AAC.00102-15.

27. Krzeska L, Yeates RA, Pfaff G. Single dose intravenous pharmacokinetics of fluconazole infants. Drugs Exp Clin Res. 1993;19(6):267-71.

28. Seay RE, Larson TA, Toscano JP, Bostrom BC, O'Leary MC, Uden DL. Pharmacokinetics of fluconazole in immune-compromised children with leukemia or other hematologic disease. Pharmacotherapy. 1995;15(1):52-8.

29. Buck ML. Pharmacokinetic changes during extracorporeal membrane oxygenation: implications for drug therapy of neonates. Clin Pharmacokinet. 2003;42(5):403-17. https://doi.org/10.2165/ 00003088-200342050-00001.

30. Gerhart JG, Watt KM, Edginton A, Wade KC, Salerno SN, Benjamin DK, et al. Physiologically-based pharmacokinetic modeling of fluconazole using plasma and cerebrospinal fluid samples from preterm and term infants. CPT Pharmacometr Syst Pharmacol. 2019;8(7):500-10. https://doi.org/10.1002/psp4.12414.

31. Watt KM, Cohen-Wolkowiez M, Barrett JS, Sevestre M, Zhao $\mathrm{P}$, Brouwer KLR, et al. Physiologically based pharmacokinetic approach to determine dosing on extracorporeal life support: fluconazole in children on ECMO. CPT Pharmacometr Syst Pharmacol. 2018;7(10):629-37. https://doi.org/10.1002/psp4.12338.

32. EMA. List of nationally authorised medicinal products: itraconazole 2017. https://www.ema.europa.eu/en/documents/psusa/itrac onazole-list-nationally-authorised-medicinal-products-psusa/ 00001798/201703_en.pdf. Accessed 16 Apr 2020.

33. CBG-MEB. Itraconazole. https://www.geneesmiddeleninform atiebank.nl. Accessed 25 Nov 2020.

34. Barone JA, Moskovitz BL, Guarnieri J, Hassell AE, Colaizzi JL, Bierman RH, et al. Enhanced bioavailability of itraconazole in hydroxypropyl-beta-cyclodextrin solution versus capsules in healthy volunteers. Antimicrob Agents Chemother. 1998;42(7):1862-5.

35. van Peer A, Woestenborghs R, Heykants J, Gasparini R, Gauwenbergh $\mathrm{G}$. The effects of food and dose on the oral systemic availabilityof itraconazole in healthy subjects. Eur J Clin Pharmacol. 1989;36:423-6.

36. Matthieu L, De Doncker P, Cauwenbergh G, Woestenborghs R, van de Velde V, Janssen PA, et al. Itraconazole penetrates the nail via the nail matrix and the nail bed-an investigation in onychomycosis. Clin Exp Dermatol. 1991;16(5):374-6. https://doi.org/ 10.1111/j.1365-2230.1991.tb00405.x.

37. Watkins DN, Badcock NR, Thompson PJ. Itraconazole concentrations in airway fluid and tissue. Br J Clin Pharmacol. 1992;33(2):206-7. https://doi.org/10.1111/j.1365-2125.1992. tb04030.x.
38. Felton T, Troke PF, Hope WW. Tissue penetration of antifungal agents. Clin Microbiol Rev. 2014;27(1):68-88. https://doi.org/10. 1128/cmr.00046-13.

39. Abdel-Rahman SM, Jacobs RF, Massarella J, Kauffman RE, Bradley JS, Kimko HC, et al. Single-dose pharmacokinetics of intravenous itraconazole and hydroxypropyl- $\beta$-cyclodextrin in infants, children, and adolescents. Antimicrob Agents Chemother. 2007;51(8):2668-73. https://doi.org/10.1128/AAC.00297-07.

40. Kim H, Shin D, Kang HJ, Yu KS, Lee JW, Kim SJ, et al. Successful empirical antifungal therapy of intravenous itraconazole with pharmacokinetic evidence in pediatric cancer patients undergoing hematopoietic stem cell transplantation. Clin Drug Invest. 2015;35(7):437-46. https://doi.org/10.1007/s40261-015-0297-3.

41. Conway SP, Etherington C, Peckham DG, Brownlee KG, Whitehead A, Cunliffe H. Pharmacokinetics and safety of itraconazole in patients with cystic fibrosis. J Antimicrob Chemother. 2004;53(5):841-7. https://doi.org/10.1093/jac/dkh175.

42. de Repentigny L, Ratelle J, Leclerc JM, Cornu G, Sokal EM, Jacqmin P, et al. Repeated-dose pharmacokinetics of an oral solution of itraconazole in infants and children. Antimicrob Agents Chemother. 1998;42(2):404-8.

43. Schmitt C, Perel Y, Harousseau JL, Lemerle S, Chwetzoff E, le Moing JP, et al. Pharmacokinetics of itraconazole oral solution in neutropenic children during long-term prophylaxis. Antimicrob Agents Chemother. 2001;45(5):1561-4. https://doi.org/10.1128/ aac.45.5.1561-1564.2001.

44. Groll AH, Wood L, Roden M, Mickiene D, Chiou CC, Townley E, et al. Safety, pharmacokinetics, and pharmacodynamics of cyclodextrin itraconazole in pediatric patients with oropharyngeal candidiasis. Antimicrob Agents Chemother. 2002;46(8):2554-63. https://doi.org/10.1128/aac.46.8.2554-2563.2002.

45. Hennig S, Wainwright CE, Bell SC, Miller H, Friberg LE, Charles BG. Population pharmacokinetics of itraconazole and its active metabolite hydroxy-itraconazole in paediatric cystic fibrosis and bone marrow transplant patients. Clin Pharmacokinet. 2006;45(11):1099-114. https://doi.org/10.2165/00003088-20064 5110-00004.

46. EMA. Vfend. https://www.ema.europa.eu/en/medicines/human/ EPAR/vfend. Accessed 9 Apr 2020.

47. Purkins L, Wood N, Kleinermans D, Greenhalgh K, Nichols D. Effect of food on the pharmacokinetics of multiple-dose oral voriconazole. Br J Clin Pharmacol. 2003;56(Suppl. 1):17-23. https:// doi.org/10.1046/j.1365-2125.2003.01994.x.

48. Lutsar I, Roffey S, Troke P. Voriconazole concentrations in the cerebrospinal fluid and brain tissue of guinea pigs and immunocompromised patients. Clin Infect Dis. 2003;37(5):728-32. https://doi.org/10.1086/377131.

49. Hariprasad SM, Mieler WF, Holz ER, Gao H, Kim JE, Chi J, et al. Determination of vitreous, aqueous, and plasma concentration of orally administered voriconazole in humans. Arch Ophthalmol. 2004;122(1):42-7. https://doi.org/10.1001/archopht.122.1.42.

50. Driscoll TA, Frangoul H, Nemecek ER, Murphey DK, Yu LC, Blumer J, et al. Comparison of pharmacokinetics and safety of voriconazole intravenous-to-oral switch in immunocompromised adolescents and healthy adults. Antimicrob Agents Chemother. 2011;55(12):5780-9. https://doi.org/10.1128/aac.05010-11.

51. Driscoll TA, Yu LC, Frangoul H, Krance RA, Nemecek E, Blumer J, et al. Comparison of pharmacokinetics and safety of voriconazole intravenous-to-oral switch in immunocompromised children and healthy adults. Antimicrob Agents Chemother. 2011;55(12):5770-9. https://doi.org/10.1128/aac.00531-11.

52. Walsh TJ, Driscoll T, Milligan PA, Wood ND, Schlamm H, Groll $\mathrm{AH}$, et al. Pharmacokinetics, safety, and tolerability of voriconazole in immunocompromised children. Antimicrob Agents Chemother. 2010;54(10):4116-23. https://doi.org/10.1128/aac. 00896-10. 
53. Michael C, Bierbach U, Frenzel K, Lange T, Basara N, Niederwieser D, et al. Voriconazole pharmacokinetics and safety in immunocompromised children compared to adult patients. Antimicrob Agents Chemother. 2010;54(8):3225-32. https://doi.org/ 10.1128/AAC.01731-09.

54. Mori M, Kobayashi R, Kato K, Maeda N, Fukushima K, Goto H, et al. Pharmacokinetics and safety of voriconazole intravenous-tooral switch regimens in immunocompromised japanese pediatric patients. Antimicrob Agents Chemother. 2015;59(2):1004-13. https://doi.org/10.1128/AAC.04093-14.

55. Neely M, Rushing T, Kovacs A, Jelliffe R, Hoffman J. Voriconazole pharmacokinetics and pharmacodynamics in children. Clin Infect Dis. 2010;50(1):27-36. https://doi.org/10.1086/648679.

56. Carlesse FADMC, de Araujo OR, Marques LMA, Silva DCBD, Senerchia AA, Petrilli AS. A pharmacokinetic model for voriconazole in a highly diversified population of children and adolescents with cancer. Mycoses. 2019;62(4):399-404. https://doi. org/10.1111/myc. 12899 .

57. Friberg LE, Ravva P, Karlsson MO, Liu P. Integrated population pharmacokinetic analysis of voriconazole in children, adolescents, and adults. Antimicrob Agents Chemother. 2012;56(6):3032-42. https://doi.org/10.1128/aac.05761-11.

58. Gastine S, Lehrnbecher T, Müller C, Farowski F, Bader P, Ullmann-Moskovits J, et al. Pharmacokinetic modeling of voriconazole to develop an alternative dosing regimen in children. Antimicrob Agents Chemother. 2018;62(1):e01194-e1217. https://doi. org/10.1128/AAC.01194-17.

59. Muto C, Shoji S, Tomono Y, Liu P. Population pharmacokinetic analysis of voriconazole from a pharmacokinetic study with immunocompromised Japanese pediatric subjects. Antimicrob Agents Chemother. 2015;59(6):3216-23. https://doi.org/10.1128/ aac.04993-14.

60. Neely M, Margol A, Fu X, van Guilder M, Bayard D, Schumitzky $\mathrm{A}$, et al. Achieving target voriconazole concentrations more accurately in children and adolescents. Antimicrob Agents Chemother. 2015;59(6):3090-7. https://doi.org/10.1128/aac.00032-15.

61. Walsh TJ, Karlsson MO, Driscoll T, Arguedas AG, Adamson P, Saez-Llorens X, et al. Pharmacokinetics and safety of intravenous voriconazole in children after single- or multiple-dose administration. Antimicrob Agents Chemother. 2004;48(6):2166-72. https:// doi.org/10.1128/aac.48.6.2166-2172.2004.

62. Karlsson MO, Lutsar I, Milligan PA. Population pharmacokinetic analysis of voriconazole plasma concentration data from pediatric studies. Antimicrob Agents Chemother. 2009;53(3):935-44. https://doi.org/10.1128/aac.00751-08.

63. Knight-Perry J, Jennissen C, Long SE, Hage S, DeFor TE, Chan WT, et al. A phase I dose finding study of intravenous voriconazole in pediatric patients undergoing hematopoietic cell transplantation. Bone Marrow Transplant. 2020;55(5):955-64. https://doi. org/10.1038/s41409-019-0757-0.

64. Zane NR, Thakker DR. A physiologically based pharmacokinetic model for voriconazole disposition predicts intestinal first-pass metabolism in children. Clin Pharmacokinet. 2014;53(12):117182. https://doi.org/10.1007/s40262-014-0181-y.

65. Yanni SB, Annaert PP, Augustijns P, Ibrahim JG, Benjamin DK $\mathrm{Jr}$, Thakker DR. In vitro hepatic metabolism explains higher clearance of voriconazole in children versus adults: role of CYP2C19 and flavin-containing monooxygenase 3. Drug Metab Dispos. 2010;38(1):25-31. https://doi.org/10.1124/dmd.109.029769.

66. EMA. EPAR summary for the public: Noxafil. 2014. https://www. ema.europa.eu/en/medicines/human/EPAR/noxafil. Accessed 6 Apr 2020.

67. Krishna G, Ma L, Martinho M, Preston RA, O’Mara E. A new solid oral tablet formulation of posaconazole: a randomized clinical trial to investigate rising single- and multiple-dose pharmacokinetics and safety in healthy volunteers. J Antimicrob
Chemother. 2012;67(11):2725-30. https://doi.org/10.1093/jac/ dks268.

68. Courtney R, Pai S, Laughlin M, Lim J, Batra V. Pharmacokinetics, safety, and tolerability of oral posaconazole administered in single and multiple doses in healthy adults. Antimicrob Agents Chemother. 2003;47(9):2788-95. https://doi.org/10.1128/aac. 47.9.2788-2795.2003.

69. Courtney R, Wexler D, Radwanski E, Lim J, Laughlin M. Effect of food on the relative bioavailability of two oral formulations of posaconazole in healthy adults. Br J Clin Pharmacol. 2004;57(2):218-22. https://doi.org/10.1046/j.1365-2125.2003. 01977.x.

70. Kersemaekers WM, Dogterom P, Xu J, Marcantonio EE, de Greef $\mathrm{R}$, Waskin H, et al. Effect of a high-fat meal on the pharmacokinetics of 300-milligram posaconazole in a solid oral tablet formulation. Antimicrob Agents Chemother. 2015;59(6):3385-9. https:// doi.org/10.1128/aac.05000-14.

71. Blennow O, Eliasson E, Pettersson T, Pohanka A, Szakos A, El-Serafi I, et al. Posaconazole concentrations in human tissues after allogeneic stem cell transplantation. Antimicrob Agents Chemother. 2014;58(8):4941-3. https://doi.org/10.1128/AAC. 03252-14.

72. Ruping MJ, Albermann N, Ebinger F, Burckhardt I, Beisel C, Muller $\mathrm{C}$, et al. Posaconazole concentrations in the central nervous system. J Antimicrob Chemother. 2008;62(6):1468-70. https://doi.org/10.1093/jac/dkn409.

73. Ghosal A, Hapangama N, Yuan Y, Achanfuo-Yeboa J, Lannucci $\mathrm{R}$, Chowdhury S, et al. Identification of human UDP-glucuronosyl transferase enzyme(s) responsible for the glucuronidation of posaconazole. Drug Metab Dispos. 2004;32(2):267-71.

74. Arrieta AC, Sung L, Bradley JS, Zwaan CM, Gates D, Waskin $\mathrm{H}$, et al. A non-randomized trial to assess the safety, tolerability, and pharmacokinetics of posaconazole oral suspension in immunocompromised children with neutropenia. PLoS ONE. 2019;14(3):e0212837. https://doi.org/10.1371/journal.pone.02128 37.

75. Vanstraelen K, Colita A, Bica AM, Mols R, Augustijns P, Peersman N, et al. Pharmacokinetics of posaconazole oral suspension in children dosed according to body surface area. Pediatr Infect Dis J. 2016;35(2):183-8. https://doi.org/10.1097/inf.0000000000 000963.

76. Groll AH, Abdel-Azim H, Lehrnbecher T, Steinbach WJ, Paschke A, Mangin E, et al. Pharmacokinetics and safety of posaconazole intravenous solution and powder for oral suspension in children with neutropenia: an open-label, sequential dose-escalation trial. Int J Antimicrob Agents. 2020;56(3):106084. https://doi.org/10. 1016/j.ijantimicag.2020.106084.

77. Boonsathorn S, Cheng I, Kloprogge F, Alonso C, Lee C, Doncheva $\mathrm{B}$, et al. Clinical pharmacokinetics and dose recommendations for posaconazole in infants and children. Clin Pharmacokinet. 2019;58(1):53-61. https://doi.org/10.1007/s40262-018-0658-1.

78. EMA. Cresemba. https://www.ema.europa.eu/en/medicines/ human/EPAR/cresemba. Accessed 06 June 2020.

79. Schmitt-Hoffmann A, Desai A, Kowalski D, Pearlman H, Yamazaki T, Townsend R. Isavuconazole absorption following oral administration in healthy subjects is comparable to intravenous dosing, and is not affected by food, or drugs that alter stomach pH. Int J Clin Pharmacol Ther. 2016;54(8):572-80. https:// doi.org/10.5414/cp202434.

80. Schmitt-Hoffmann AH, Kato K, Townsend R, Potchoiba MJ, Hope WW, Andes D, et al. Tissue distribution and elimination of isavuconazole following single and repeat oral-dose administration of isavuconazonium sulfate to rats. Antimicrob Agents Chemother. 2017;61(12):e01292-e1317. https://doi.org/10.1128/aac.

81. Decembrino N, Perruccio K, Zecca M, Colombini A, Calore E, Muggeo P, et al. A case series and literature review of 
isavuconazole use in pediatric patients with hemato-oncologic diseases and hematopoietic stem cell transplantation. Antimicrob Agents Chemother. 2020;64(3):e01783-e1819. https://doi.org/10. 1128/AAC.01783-19.

82. FDA. Drug development and drug interactions: table of substrates, inhibitors and inducers. https://www.fda.gov/drugs/drug-inter actions-labeling/drug-development-and-drug-interactions-tablesubstrates-inhibitors-and-inducers. Accessed 12 Apr 2020.

83. FDA. Clinical pharmacology review: posaconazole. 2015. https:// www.fda.gov/media/87944/download. Accessed 15 Apr 2020. 